ISSN: 0213-2079 - ISSN electrónico: 2386-3889

DOI: https://doi.org/10.14201/shhmo202143271104

\title{
LOS PROBLEMAS DE INTERPRETACIÓN DE LAS FUENTES DOCUMENTALES SOBRE BEATRIZ GALINDO, LA LATINA
}

\section{Issues of interpretation of the manuscript and printed documentary sources on Beatriz Galindo, La Latina}

\author{
Ana María CARABIAS TORRES ${ }^{1}$ \\ Universidad de Salamanca \\ anacarabias@usal.es
}

Fecha de recepción: 26/07/2021

Fecha de aceptación: 23/11/2021

RESUMEN: Durante muchos años se creyó que Beatriz Galindo, llamada la Latina, había sido maestra de la reina Isabel la Católica entre 1486 y 1504, pero algunas investigaciones han puesto de manifiesto que durante este periodo de tiempo solo fue criada doméstica de la Casa de la Reina. Existen problemas de interpretación de las fuentes documentales sobre Beatriz Galindo. El objetivo de este estudio es hacer un análisis del contenido de estas fuentes documentales tratando de explicar sus dificultades interpretativas a partir de las distintas épocas de la vida de este personaje. Estas diferentes fases vitales (como criada, como esposa de un personaje influyente y como viuda acaudalada) pueden justificar la disparidad y las contradicciones de su biografía.

1. Miembro del Grupo de Investigación Reconocido: Historia de los Derechos Humanos. $\mathrm{HDH}$ (Universidad de Salamanca). Debo agradecer las observaciones a este texto que me ha hecho el profesor Juan José Mateos Díez, toda útiles. Abreviaturas utilizadas: AGS: Archivo General de Simancas; CCA: Libros de Cámara; CED: Cédula; RGS: Registro del Sello de Corte; AHN: Archivo Histórico Nacional; AHNobleza: Archivo Histórico de la Nobleza; Leg.: legajo; f./ff.: folio/folios; r: recto (folio); v: verso o vuelto (folio); s.p.: sin paginar. Todos los recursos web citados están activos hoy, 15 de julio de 2021. 
Palabras clave: La Latina; Corte de Isabel la Católica; puellae doctae del Renacimiento; mujeres sabias.

ABSTRACT: For many years it was believed that Beatriz Galindo, called the Latina, had been Queen Isabel la Católica's teacher between 1486 and 1504, but some investigations have shown that during this period of time she was only a domestic servant of the Queen's House. There are problems of interpretation of the documentary sources on Beatriz Galindo. The objective of this study is to analyze the content of these documentary sources, trying to explain their interpretive difficulties from the different periods of this character's life. These different life phases (as a maid, as the wife of an influential person, and as a wealthy widow) can justify the disparity and contradictions in her biography.

Keywords: La Latina; Court of Isabel la Católica; puellae doctae of the Renaissance; wise women.

El desarrollo del feminismo desde 1960 promovió un avance inusitado de los estudios históricos de género, lo que derivó en la revisión y el crecimiento de la información relativa a las mujeres relevantes del pasado. Este interés renovado condujo pronto a la recuperación de nombres y hechos de personajes históricos antes poco estudiados, así como a subrayar e incluso a magnificar los datos documentales que se iban localizando sobre estas mujeres.

Uno de los resultados palpables de este proceso fue la puesta en práctica de una terminología semánticamente precisa con la que se denominó a las puellae doctae: expresión latina con la que se ha generalizado la referencia historiográfica a jóvenes mujeres cultas, con conocimientos de latín, que vivieron en la Península Ibérica en la época del Renacimiento. Entre las más notables desde Clemencín (1820: 410) se recuerda a Francisca de Nebrija, Florencia Pinar, María Pacheco, Luisa Siega, Juana Contreras, Teresa de Cartagena, Feliciana Enríquez de Guzmán, Álvara de Alba, Luisa (llamada Lucía por error de Marineo) de Medrano, Beatriz de Bobadilla, Beatriz Galindo, Cecilia Morillas, Clara Chitera... Sus nombres no eran nuevos en la historiografía, pero sí la matización de los méritos que se han aducido para reivindicar su valor y reavivar el conocimiento de los mismos. La primera consecuencia ha sido un espectacular progreso de los estudios históricos sobre este sector social, generalizado y extendido en una amplia producción editorial ${ }^{2}$.

2. Un estado de la cuestión reciente sobre las puellae doctae se encuentra en Carabias, 2019: notas 3 (pp. 181-182) y nota 60 (pp. 192-193). 
A pesar de haber un cierto consenso en las publicaciones de los primeros años del siglo XXI sobre las extraordinarias facultades de estas «mujeres sabias», hubo algunos historiadores que desestimaron varias de las atribuciones consensuadas sobre ellas y que establecieron objeciones importantes frente a algunas de las afirmaciones: Esperabé (1914), reflexionando sobre el tema, decidió no incluir a Luisa de Medrano en la lista de los catedráticos de la Universidad de Salamanca. Antonio de la Torre (1954, 1956 y 1957), que estudió las cuentas del tesorero de la reina Isabel la Católica y a los maestros de su corte, concluyó que la Latina había sido criada de la soberana; la misma conclusión a la que llegó Beltrán de Heredia (1971). El conocimiento de la documentación de la casa Bornos (heredera de la familia de la Latina) catalogada por Porras, convierte las investigaciones de este profesor en cruciales para el tema que nos ocupa: En el estudio sobre Francisco Ramírez, el Artillero, esposo de Galindo (Porras, 1996), reconocía que, hasta los estudios de Torre, se habían hecho biografías «con un valor más laudatorio que histórico» de la Latina; y en el trabajo biográfico sobre Beatriz (Porras, 2006), se expresa con meridiana claridad la condición de criada del personaje y las circunstancias de su sorprendente ascenso social. En los últimos años, Cristina Segura, en la última biografía sobre la Latina (Segura, s.a.), ha reconocido que esta solo pudo haber sido maestra informal de la reina. Pilar Rábade (2016), por su parte, animaba al lector a deconstruir el personaje. Los últimos toques de atención frente al entusiasmo de la historiografía de género previa lo representan los estudios de Mateos Díez y Carabias, de 2019, que pusieron en tela de juicio algunos de los méritos atribuidos a Luisa de Medrano como primera catedrática universitaria de derecho canónico en 1508, y a Beatriz Galindo, la Latina, como maestra de la reina.

Considerando el estado de la cuestión descrito, a día de hoy se puede afirmar, sin ningún género de dudas, que Beatriz Galindo fue una criada y no una maestra en la corte de los Reyes Católicos. Pero, sorprendentemente, la asimilación de esta nueva interpretación por parte de los investigadores parece moverse con similar lentitud a como lo hacen las mentalidades, de forma que, de momento solo hemos encontrado una publicación científica que se haya hecho eco de este cambio interpretativo; se trata de una traducción y estudio de una obra de Teresa de Cartagena editada por Ghislain Baury (Baury, 2021: 24). También se ha cambiado el contenido de la ficha de personaje en el Portal de Archivos Españoles (PARES) sustituyendo el anterior oficio de maestra por el de criada; pero la mayoría de los investigadores que han publicado sobre el tema en los últimos dos años sigue arrastrando datos históricos confusos y erróneos ${ }^{3}$, por lo que consideramos oportuna la presente reflexión, cuyo

3. Las investigaciones de Pelaz Flores, Cahill, Martínez Alcorco, Sánchez Salor o Reder, todas del año 2020, no muestran las nuevas interpretaciones historiográficas. Cabe subrayar, por confuso, el estudio de Grande del Brío (2020) sobre Galindo y Medrano. Véase la reseña de Carabias y Mateos a Grande del Brío (2021), en línea. 
objetivo no es hacer una biografía de Beatriz ${ }^{4}$, sino realizar un análisis del contenido de las fuentes documentales tratando de explicar las dificultades interpretativas a las que pueden enfrentarse los investigadores que se acerquen a este tema.

Existen muchos datos documentales sobre la Latina, tanto manuscritos como impresos. El mayor de los problemas que deriva de la información recogida en ellos es que - según pretendemos explicar-Beatriz tuvo dos fases cronológicas muy diferenciadas en su vida; fases de las que derivaron sendos conjuntos informativos con noticias sobre ella aparentemente chocantes e incluso contradictorias; y no conozco a nadie que lo haya observado y analizado. Una pregunta salta inmediatamente cuando se leen las últimas publicaciones sobre ella: si realmente fue solo una criada ¿Cómo tuvo tanta familiaridad con los reyes y por qué recibió tantas y tan importantes donaciones de los monarcas? ¿Cómo fue tan rica, tanto como para fundar tres instituciones de caridad?

En nuestra opinión, Beatriz fue primero una criada y se la consideró y trató como tal; pero después ascendió socialmente de forma inmediata e inesperada, no por ser maestra, que nunca lo fue, sino como consecuencia de la influencia y los bienes económicos que llegaría a heredar de su marido. Este estudio tratará de explicarlo.

\section{1. ¿SON CONTRADICTORIOS ALGUNOS DATOS QUE OFRECEN LAS FUENTES DOCUMENTALES SOBRE BEATRIZ GALINDO?}

\subsection{Datos de la contabilidad de la Casa de la Reina}

Beatriz era hija de Juan López de Gricio, escribano de Salamanca en 1456, que al morir su esposa tomó el hábito de san Agustín. Ante la falta de recursos económicos suficientes, la niña recibió educación en lengua latina con el fin de abaratar la dote de ingreso en un convento. Sin embargo, estos conocimientos le permitieron, sin que las fuentes expliquen cómo, entrar al servicio de la reina.

La primera noticia que confirma la estancia de la Latina en la corte al menos desde finales de 1486 es un apunte del tesorero real, Gonzalo de Baeza, el 15 de enero de 1487, donde anota el gasto de un «gonete» y una «faldrilla» para Beatriz, la Latina (Torre, 1955, I: 162).

¿Qué hacía Beatriz en la corte? Sabemos que el oficio y los bienes materiales son un principio preciso de consideración social en cualquier momento y lugar, aunque sean parámetros relativos. Los oficios femeninos de la Casa de la Reina

4. Pueden encontrarse datos biográficos precisos en Porras, 2006 y Segura, s.a.; datos completivos en Torre, 1957; Arteaga y Falguera, 1975; Matilla, 2000; Arteaga, 2007; Andreu, 2009; Belda, 2013 y Sainz, 2020. 
Isabel (también tenía empleados varones), en los años que trabajó en ella Galindo, fueron los siguientes:

TABLA 1: Número, tipología y salario de las mujeres de la Casa de Isabel la Católica ${ }^{5}$

\begin{tabular}{|c|c|c|}
\hline $\begin{array}{l}\text { Empleadas en la Casa de la Reina } \\
\text { (168 mujeres) }\end{array}$ & $\begin{array}{c}\text { Salario anual } \\
\text { (maravedís) }\end{array}$ & $\begin{array}{l}\text { N. de mujeres } \\
\text { con ese salario }\end{array}$ \\
\hline \multirow{12}{*}{$\begin{array}{l}\text { Damas y dueñas } \\
\text { (32 mujeres) }\end{array}$} & 250000 & 1 \\
\hline & 200000 & 1 \\
\hline & 140000 & 1 \\
\hline & 130000 & 1 \\
\hline & 100000 & 4 \\
\hline & 80000 & 1 \\
\hline & 78000 & 1 \\
\hline & 66000 & 2 \\
\hline & 60000 & 2 \\
\hline & 50000 & 2 \\
\hline & 40000 & 15 \\
\hline & 34000 & 1 \\
\hline $\begin{array}{c}\text { Doncellas } \\
\text { (85 jóvenes) }\end{array}$ & 27000 & 85 \\
\hline \multirow{5}{*}{$\begin{array}{c}\text { Criadas } \\
\left(51 \text { mujeres. La Latina entre ellas }{ }^{6}\right)\end{array}$} & 15000 & 18 \\
\hline & 12000 & 2 \\
\hline & 10000 & 20 \\
\hline & 8000 & 5 \\
\hline & 6000 & 6 \\
\hline
\end{tabular}

Beatriz Galindo figura entre las dieciocho mozas de cámara, el grupo salarial más alto dentro del servicio doméstico de la Casa. Dependiendo del año concreto, se le paga su sueldo en concepto de «criada», «moza latina», «criada de la ynfante»

5. Elaboración propia a partir de los datos de González Marrero, 2009, II: 878-885.

6. Las otras diecisiete mozas de cámara eran: Beatriz de Paredes, hija de Sancho de Paredes; Beatriz Gómez, Beatriz Marque, Dña. Isabel, hija de Costan; Dña. Leonor de Mendaño, mujer del comendador Guevara; Dña. María de Alcaraz, ama de la reina y la princesa; Dominga Ponce, hija del doctor Ponce; hija de madona Marque, Inés de Albornoz, Isabel Cuello, Isabel de Sion, mujer de Guillén Márquez; Isabel Marque, Marina Ruiz, Violante de Albión, e Inés Ortega, hija de Marina Ruiz (González Marrero, 2009: II, 883). 
(se refiere a doña Juana, en 1489) o «moza de cámara de la Reina» (en 1490), el máximo puesto que llegó a alcanzar en la corte (Torre, 1955-1956).

También en cartas y en otros documentos redactados por orden de los reyes se la denomina como «criada»: En varias órdenes de la reina a Sancho de Paredes la soberana se refiere a «Beatriz Galindo, mi criada» ${ }^{7}$ y ella firma el recibí de esta entrega como «Beatriz Galindo, criada de la reina» ${ }^{8}$; en nota de la reina a Francisco de Rojas: «...sobre el negocio que toca al hospital que Beatriz Galindo, mi criada, face en Madrid»' ; el rey Fernando se refiere a Beatriz como la «criada que fue de la señora reina doña Isabel, mi mujer» en varios documentos recogidos por Beltrán (Beltrán, 1971, III: 308, 310, 311 y 312). No es verdad, como se ha dicho en varios estudios, que en las cuentas del tesorero se lea que, desde 1487, la reina estaba recibiendo clases de Beatriz Galindo. Quienes lo dicen no han leído esas cuentas.

En algunos textos impresos (ajenos por tanto a los datos contables) se habla de la Latina como «camarera». Lucio Marineo Sículo se refiere a ella como «camarera consejera de la misma reyna» (Marineo Sículo, 1530b: CCLII v). También Pérez de Moya en su Varia historia de sanctas e illustres mujeres, y otros, aluden a la Latina como «camarera de la serenísima Reyna Católica doña Isabel». Márquez de la Plata (2005) atribuye este mismo oficio de camarera a Beatriz de Bobadilla (pero esta no figura como tal en la nómina salarial de la Casa de la Reina), aunque sí aparece en las cuentas del tesorero Isabel Cuello como «camarera de la reina». El Diccionario de Autoridades cita a Beatriz de Bobadilla como «camarera mayor» y lo hace en una entrada distinta de la de «camarera», definiendo a esta última como «criada»; una camarera es la cubicularia (Nebrija, 1495: 32.2); «La mujer que sirve y cuida de vestir y tocar a su ama... Lat. cubicularia». En cambio, la «camarera mayor» es «oficio de grande estimación en Palacio, que siempre le ocupa una Señora Grande... Precede en el coche a todas las otras criadas de los Reyes y Príncipes... Gobierna todo lo que es del quarto de la Reina, y es el Xefe de todas las mujeres de Palacio» (Real Academia Española, 1729: 86). Luis de Salazar de Castro refutó a Pellicer, defendiendo que la reina solo tuvo dos camareras mayores: Clara Alvarnaes e Inés Manrique, sucesivamente (Cf. Llanos, 1920: 30).

¿Tenía entonces mayor consideración el oficio de camarera que el de moza de cámara? A juzgar por el salario, no, porque tanto la Latina como Isabel Cuello cobraban sendos 15000 maravedís anuales por su trabajo (Torre, 1955, I: 507),

7. 27 de octubre de 1503. La reina a Sancho de Paredes: «que entregue luego a Beatriz Galindo, mi criada, una faldilla de damasco carmesí» (AHN, Diversos-Colecciones,11,N.857). 8 de enero de 1504. La reina a Paredes: "entregue a su criada trece varas de cinta carmesí» (AGS,CCA.9,f.18).

8. AHN, Diversos-Colecciones, 11, N.857.

9. 10 de julio de 1503. AGS,CCA,CED,6,131,4. En ese momento la Latina estaba dando forma a la fundación de su hospital. 
en tanto que las damas y dueñas recibían entre 34000 y 250 000, y las doncellas 27000 maravedís anuales ${ }^{10}$.

El vocablo «moza» ha tenido siempre el mismo significado, desde que se tiene noticia de su uso hasta el presente: mozo y moza se ha equiparado semánticamente a «joven», y, en una segunda acepción, a «criado». En el vocabulario de Nebrija (1516: 102.1) se recoge: «moça de servicio, famula». En Covarrubias (1611:1002.2) se dice «...Llamamos moços y moças a los que siruen amos, porque para ellos han de ser libres, que no dependan de otro, y juntamente con fuerças y vigor para servir». Teniendo en cuenta el sentido de esa voz y del oficio que tenía en la época quien así se le llamaba, Torre confirmó que los empleos de «moza» o «moza de cámara», eran equiparables en ese momento a los de «mozo de capilla», «mozo de espuelas» o «mozos de lebreles» (Torre, 1956, II: 258-259); lo recuerda Torre, y vemos que efectivamente así aparece expresado en los vocabularios y diccionarios de la época.

De igual modo la palabra «cámara» significa alcoba o aposento «cámara donde dormimos» (Alcalá, 1505: 85); «donde se duerme ordinariamente» (Covarrubias, 1611: 357). Mientras que el término «mozo» o «moza» ha conservado su significado, la palabra «cámara» está en desuso hoy como «dormitorio». Así pues, no cabe ninguna duda de que Beatriz fue criada o moza de cámara en la Casa de la Reina, circunstancia que ya en sí misma denota un cierto estatus social. No era lo mismo ser criada de una familia campesina que de la reina.

\subsection{Las atenciones y regalos de la reina a Beatriz Galindo, su criada}

En varias ocasiones los historiadores han considerado signos de distinción y singularidad los regalos que la reina hizo a la Latina.

Afortunadamente se ha conservado el libro del limosnero de la reina del año 1487, en el tiempo en que Galindo acababa de ingresar en la corte. En él se anotan las entregas del limosnero Pedro de Toledo a empleados de la Casa Real, entre ellos a la Latina; bastantes cosas en un solo año: «Di en [el lugar de] Medinaçeli por dos pares de calças coloradas para la Latina e para otra de casa tres reales, e por unos guantes de lana para María de Robles veinte maravedíes, e por otros guantes de lana para Núñez veinte e cinco...» (Benito, 1989, n. $\left.{ }^{\circ} 135\right)$. A los pocos días el limosnero compró XVI varas castellanas para «mangas [par]a dos camisas a doña Françisquita e de Beatriz la Latina...» (Benito, 1989, n. ${ }^{\circ} 150$ y 151). Estando la corte en Benavente, Toledo anota: «di para quatro varas de paño para faldetas para Beatriz la Latina, a

10. El sueldo de Beatriz como moza era bajo en comparación con el resto de los oficios de la corte. Otros salarios coetáneos: 403880 maravedís el mayordomo mayor del príncipe; 167980 maravedís el contador mayor; 127000 maravedís el lugarteniente del contador mayor, año 1490-1491. Estas y otras retribuciones en Martín Postigo, 1959: 318-320. 
quatroçientos maravedíes la vara, mil e seisçientos maravedíes» (Benito, 1989, n. ${ }^{\circ}$ 556). Poco después, en Salamanca: «Di para el enforro de las faldetas de Beatriz la Latina, para diez varas de frisa, a treinta e ocho la vara, que montan 480 [por 380]» (Benito, 1989, n. ${ }^{\circ}$ 568).

Recibir tela para unas calzas, una falda, unas mangas o unos guantes parece realmente que entra dentro del rango del socorro o la caridad ¿Fueron «Francisquita» y Beatriz las únicas beneficiarias de estas limosnas en ese ejercicio contable concreto? En absoluto. Este libro está plagado de limosnas a trabajadores de la corte. Por ejemplo, estando en Ponferrada, se entregaron limosnas de entre 5000 y 2000 maravedís a todos y cada uno de los capellanes y cantores; 1000 a los mozos de capilla, monteros y empleados de la «cámara»; 2000 a los reposteros de camas; entre 2000 y 1500 a los «reyes de $\operatorname{armas}^{11}$ y ballesteros de mazas»; 2000 a cada paje; 1500 a los porteros; entre 3000 y 1000 a los cocineros; entre 1000 y 2000 a «otros oficiales de la casa»; 1000 a los «moços de espuelas»; entre 1000 y 2000 a los escuderos de pie; 10000 al doctor Puebla y distintas cantidades a otros colaboradores (Benito, 1989: n. ${ }^{\circ}$ 461-474). También hubo muchas donaciones de objetos. Considerando que Beatriz ganaba 15000 maravedís al año, una limosna de 5000 como las entregadas a capellanes y cantores parece una gran dádiva.

Se observa, pues, que estas entregas fueron habituales y constantes en la corte. La liberalidad real iba de la simple dádiva al verdadero mecenazgo (Salvador Miguel, 2008). Aunque no se han localizado libros del limosnero posteriores, sí que aparecen apuntes de caridad hacia «su criada» Beatriz en fechas ulteriores: El 30 de octubre de 1500 la reina le hizo merced de varias piezas de ropa; el 14 de diciembre de 1500 «una mantilla de sarga recibida de Mena Ote, sastre del rey ${ }^{12}$; el 27 de octubre de 1503 «una faldilla de damasco carmesí» ${ }^{13}$, el 8 de enero de 1504 «trece varas de cinta carmesí» ${ }^{14} \ldots$

Llama la atención la generosidad limosnera de la monarca. Los contenidos del libro del limosnero demuestran que fueron frecuentísimas y muy diversificadas, geográfica y socialmente hablando, las atenciones y regalos que la reina repartió en concepto de «limosna» (así se anotan), a Beatriz y a cualquiera que pidiera en la

11. Reyes de armas: «... instrucciones y regimiento de guerra que Iulio César instituyó ciertas dignidades que hoy llamamos Reyes de armas, y estas se dauan a doce caualleros ancianos, que por mucho tiempo auían seruido en la guerra y asistido a muchas batallas y recuentros... asistiendo... en ciertos autos públicos y solemnes [y] publican algunos mandados y órdenes de Su Magestad» (Covarrubias, 1611: 1216).

12. AGS, CCA,CED, 4,259,5.

13. AHN,Diversos-Colecciones,11,N.857.

14. AGS,CCA.9,f.18. La reina siempre habla de «mi criada» también en otros documentos: AGS, CCA: CED,4,259,5; CED,4,211,3; CED,9,17,2; CED,5,77,4; CED,5,52,2; CED,5,77,3; CED,5,60,1; CED, $9,53,2$. 
«puerta» de la corte. Sin embargo, a partir del matrimonio de la Latina con Francisco Ramírez, el tipo de donativos de los reyes a su criada cambió radicalmente de contenido, como veremos en el apartado 1.4.

\section{3. ¿Pudo haber sido Beatriz maestra en la corte a pesar de lo que refleja la contabilidad de la Casa de la Reina?}

\subsubsection{Gonzalo Fernández de Oviedo}

Como ya dijimos, en multitud de libros se ha venido repitiendo que la reina llamó a Beatriz a la corte para que fuera su maestra de latín. Carabias mostró que la primera vez que se expresó esta atribución fue en Fernández de Oviedo (1478-1557), que la plasmó en dos obras que escribió de forma simultánea en la última etapa de su vida (aunque las dio por terminadas en distintas anualidades), en las que repitió frecuentemente información: el Libro de la Cámara Real del principe don Juan y Batallas y Quinquagenas.

El Libro de la Cámara Real... es «un breve tratado en el que se hace memoria acerca de la organización interna por la que se rigió la casa del príncipe don Juan (1478-1497), primogénito y único hijo varón de los Reyes Católicos», según Fabregat (Fernández de Oviedo, 2006: 76). Estaba concluido en 1548 y en él dice:

La qual Beatriz Galindo por otro nombre la llamaron la Latina, porque así lo era, e vino donzella a enseñar gramática a la Reina Católica, e le enseñó las letras latinas, e le fue tan açepta como tengo dicho (Fernández de Oviedo, 2006: 136).

En Batallas y quinquagenas, en forma de diálogos entre un alcalde y su único interlocutor, Sereno, ofrece sendos comentarios por cada «ilustrísimo personaje» de los que habla, dedicando uno de ellos a Beatriz, su esposo, sus hijos y hermano y dice:

Esa misma Latina fue Beatriz Galindo, la qual fue vna sancta mujer, e seyendo doncella e natural de la çibdad de Salamanca, hija de vn hidalgo llamado [espacio en blanco] de Grizio, honesta e virtuosa, adornada de virtudes, informada la Reyna Cathólica doña Ysabel de su persona e onestidad, e que era gentil latina, la quiso tener a par de sí en su cámara, porque enseñase a su Alteza la lengua latina... ${ }^{15}$ (Fernández de Oviedo, 1989: 149).

15. Antes de terminar la obra, el autor acometió la tarea de darle nueva forma, no dialogada, recogiendo en ella los personajes notables de la historia española; así nació Las Quincuagenas de los generosos e illustres e no menos famosos reyes, principes, duques, marqueses y condes e caballeros e personas notables de España; obra terminada, según su propia firma, el 24 de mayo de 1556 (Pérez de Tudela, s.a.). En esta nueva versión no incluyó información sobre la familia Ramírez-Galindo. 
Este texto lo redactó entre los años 1551 y 1552 (Carabias, 2019:183) (probablemente porque escribió y corrigió su contenido a lo largo de ese periodo); es decir, sesenta y un años después de que conociera a la Latina, pues él mismo aclara: «desde el año 1490, seyendo de doce años... fui llevado a la corte de los serenísimos e católicos Reyes...» (cf. Clemencín, 1820: 211). Está haciendo un relato de lo que recuerda, y parece que no recuerda con precisión, porque dice cosas distintas. En el Libro de la Cámara Real...: «E después que la reina passó de esta vida, se fue Beatriz Galindo a Madrid, e se retruxo a aquellos dos monasterios de monjas de la Conçepçión que allí ay, uno de françiscas, que el secretario y ella fundaron, e otro de gerónimas, que ella allí fundó después que acabó el primero» (Fernández de Oviedo, 2006: 136). En tanto que en Batallas y quinquagenas escribió algo diferente: «...fundó el hospital de la Conçepçión de Madrid e monasterio de monjas de Sanct Francisco, donde Dios nuestro Señor, se sirue mucho, pero no se acabó porque le atajó la muerte al secretario, más acabole la señora Beatriz Galindo» (Fernández de Oviedo, 1989: 149). Hoy sabemos que Beatriz fundó el hospital cumpliendo una manda testamentaria de el Artillero, pero tanto este hospital como los dos conventos (no uno, como dice en Batallas...: el de la Concepción Jerónima y el de la Concepción Francisca) fueron erigidos por Beatriz cuando su marido ya estaba muerto ${ }^{16}$. Fernández de Oviedo se equivoca, no recuerda con precisión, quizá porque en ese momento tiene 74 años y una larguísima peregrinación vital a sus espaldas ${ }^{17}$.

Este autor representa la única fuente documental primaria en la que se expresa el oficio de maestra de la Latina. Coincidimos con la opinión del experto Pérez

16. Recordemos que el Artillero murió en marzo de 1501. La primera noticia que tengo sobre la fundación del Hospital de la Concepción de la Madre de Dios (más conocido como «hospital de la Latina») es de 1503 (véase la nota 9); su erección respondía a una manda testamentaria de el Artillero. El primer proyecto de fundación de un convento fue de 1505 (véase nota 36). El convento de la Concepción Jerónima abrió sus puertas en 1509 (recibió para ello el apoyo de 100000 maravedís donados tiempo atrás por Isabel I con este fin); el convento de la Concepción Francisca en 1512.

17. Fernández de Oviedo, en 1493 fue mozo de cámara del príncipe don Juan, hijo de los Reyes Católicos, hasta octubre de 1497 en que muere. A partir de entonces comenzó un largo peregrinaje geográfico y laboral. Viajó por Génova, Milán, Mantua, Roma, Nápoles, Aragón, Perpiñán, Logroño, Madrid, Castilla del Oro, Santa Marta (en Indias), Santo Domingo, Plasencia, Bruselas, Madrid, Panamá, Sevilla... con distintos trayectos de ida y vuelta entre estos lugres. Trabajó sucesivamente como soldado, notario y secretario del consejo de la Inquisición, escribano de Madrid, secretario del Gran Capitán, ocupó varias escribanías en Indias, fue veedor de Castilla del Oro, procurador de tierra firme en Indias, gobernador de Santa Marta, veedor de Panamá, procurador en Cortes por Panamá y Santo Domingo. Fue empleado de Isabel de Aragón (viuda de Francisco de Gonzaga), Juan de Borja, don Fadrique (1452-1504, rey de Nápoles, hijo de Fernando I de Nápoles). Murió en la República Dominicana el 7 de junio de 1557 (Biografía en Pérez de Tudela, s.a.). 
de Tudela, en que Batallas y Quincuaguenas fue «donde su espíritu se meció en recuerdos y se expandió en reflexiones a su antojo» (Pérez de Tudela, s.a.).

A Fernández de Oviedo citan la catarata de autores posteriores que han recogido el dato de magisterio de la Latina, desde los primeros (José de Sigüenza ([15951605]1909: 83-84), Clemencín (1820: 52) o Serrano Sanz (1903: 423 y ss) hasta hoy.

\subsubsection{Lucio Marineo Sículo (1444-1536)}

Según Ramos Santana, Marineo fue invitado por Fadrique Enríquez, en 1484, a formar parte de su séquito y volver con él a España. Como todos los italianos, pasó por Salamanca y aceptó el ofrecimiento la universidad de ocupar dos cátedras: Poesía y Oratoria (1485-1497) (Jiménez Calvente, 2001: 35-36). Finalmente, trabajó en la corte desde 1497, como capellán de la reina y como cronista, hasta su muerte en 1533. Conoció y convivió a veces con Beatriz Galindo desde 1497.

Para comprender en su justa medida las palabras del cronista Marineo sobre la Latina y sobre el resto de los personajes del entramado político castellano, incluso de los propios Reyes Católicos, hay que recordar que habló de ellos en un contexto encomiástico, porque su situación laboral como cronista y el momento histórico así lo requerían; los escritos de un cronista estaban controlados por el poder.

Como trabajador de la corte y cronista, no tenía otra opción que escribir y publicar libros laudatorios que tuvieran gran repercusión. Por eso ofreció la misma obra en latín y en romance y las publicó, el mismo mes (julio de 1530) y en el mismo lugar (Alcalá de Henares, imprenta de Miguel Eguía): el texto latino llevaba por título: De rebus Hispaniae memorabilibus y su traducción casi literal: De las cosas memorables de España, obra que representó un auténtico compendio de historia de España (Cuart, 2004: 63). En ella incluyó un capítulo dedicado a las mujeres ilustres (titulado en la obra latina De quibusdam Hispaniae foeminis illustribus), colofón de otro destinado a los varones ilustres (De viribus illustribus Hispaniae). En ellas se refirió a la Latina con estas palabras:

Texto en latín: Novimus praeterea in Hispania foeminas literis illustres et memorabiles, ex quibus aliquas referre libet. Vidimus itaque Beatricem Galindam Francisci Maioritani Regii secretarii coniugem et Isabellae reginae catholicae cubiculariam simul et consiliariam literis et moribus ornatissimam. Quae cum propter alias virtutes suas, tum vero propter eruditionem, Reginae fuit quam charissima, et propter linguam latinam, qua maxime pollebat, latina fuit cognominata (Marineo Sículo, 1530a: CLXXIV v).

Texto en romance: Conocimos en España mugeres ilustres y memorables en letras y otras virtudes de las quales nombraremos algunas brevemente. Assí que vimos en el palacio de los Reyes Cathólicos a Beatriz Galindo, muger que fue de Francisco de Madrid, secretario de la reyna doña Ysabel, camarera consejera de la misma

Ediciones Universidad de Salamanca / అ@@ Stud. his., H. ${ }^{a}$ mod., 43, n. 2 (2021), pp. 71-104 
reyna, muger muy adornada de letras y sanctas costumbres. La qual assí por sus virtudes como por la doctrina singular fue muy privada y bien quista de la casa real y, por la lengua latina que hablaba sueltamente, fue dicha por sobrenombre la latina (Marineo Sículo, 1530b: CCLII v).

Grande del Brío supuso que esta era una traducción «adulterada», «grosera», «pésima», «espuria», «deleznable». Grande no sabe que esta supuesta «adulterada traducción» al romance estuvo a cargo del mismo Marineo, autor de la versión latina ${ }^{18}$, y que se publicó al mismo tiempo que el original latino, como hemos dicho ${ }^{19}$.

Según Marineo, Beatriz habría sido «camarera» - cubicularia es la que sirve en la cámara, en el vocabulario de Nebrija (1495: 37.2) - y al mismo tiempo «consejera de letras» (consiliariam literis), no maestra. Tampoco se expresa este magisterio en el capítulo dedicado a las costumbres y religión de la reina.

Obsérvese que Marineo tradujo «Isabellae reginae catholicae cubiculariam simul et consiliariam literis» por «camarera consejera de la misma reyna, muger muy adornada de letras». «Consiliaria» era la «consejera» (Covarrubias, 1611: 465,2; no se recoge antes esta palabra). Si tenemos en cuenta el interés laudatorio de Marinero en este texto, y si atendemos a lo que añade después ( «...La qual assí por sus virtudes como por la doctrina singular fue muy privada y bien quista de la casa real y, por la lengua latina que hablaba sueltamente, fue dicha por sobrenombre la latina»), cabe interpretar que el conocimiento de latín fue el mérito que condujo a Beatriz hacia un trabajo en la corte como camarera y que, por saber este idioma en un ambiente en el que esta lengua era valorada, podría aconsejar en el uso de la misma. Opino que, si Beatriz hubiera sido maestra de Isabel I, Marineo no hubiera omitido un detalle tan fundamental. No olvidemos que Marineo fue durante un tiempo maestro de los mozos de coro de la corte; conocía por experiencia la dignidad, el mérito y el valor de tan alto oficio.

A partir de estas fuentes primarias se extendió como río de pólvora por otros tantos libros y estudios la idea del magisterio de la Latina. La acaudalada fundadora de un hospital y dos conventos, que encargó obras de arte a algunos de los

18. Dentro de las 117 p. de que consta el librito de Grande del Brío, el autor repite 23 veces que la traducción del De rebus... ha sido adulterada: pp. 10, 14, 18, 21, 25, 27, 34, 76, 86, 87, 22, 98, 97, 99, 101, 108, 110 y 112, en varias de ellas lo reitera ¿Habrá forma de meter más la pata en historia?

19. Rivera Martín dice: «a dicha conclusión llega basándose en dos argumentos: primero que la versión latina y la castellana aparecieron al mismo tiempo; y segundo que Marineo solía participar de una manera muy directa en la preparación de sus obras para la imprenta: de hecho, en 1529 se le concedió por cédula del uno de mayo permiso para ausentarse de la corte y dar los últimos retoques a su libro antes de publicarlo» (Jiménez Calvente, 1966: 161; $c f$. Rivera Martín, 2000: LXXXVIII). Maestre afirma que Marineo «estaba presente en el momento de la traducción de esas partes de su obra y aprovechó la misma para introducir unos cambios que consideraba oportunos» (Maestre, 2008: 1190-1191). 
mejores artistas del momento, no podía haber sido otra cosa. Así, la noticia de su desempeño aparece en la mayoría de los historiadores anteriores al siglo XX, y en otros documentos.

\subsubsection{La reina y la educación en la corte}

La reina, que había tenido una cuidada educación (Salvador Miguel, 2004), fue muy sensible a la formación intelectual personal, familiar y de la corte en pleno, no solo por puro interés intelectual, sino incluso por lo que influye en el desarrollo personal y el cumplimiento de lo que Dios hubiera encomendado a cada uno (Val Valdivieso, 2006). Otros estudios así lo confirman (Val Valdivieso, 2011; Val Valdivieso, 2013: 14; Alvar, 2002).

No cabe duda de que tenía verdadera admiración por la lengua latina. El latín era entonces una lengua viva que se utilizaba en la diplomacia, el comercio internacional, la ciencia y la universidad. La reina también tuvo interés en los contenidos educativos que el humanismo (movimiento renacentista) promovía; la formación religioso-espiritual y el ámbito intelectual estaban conectados.

A pesar de ello, en ese tiempo y circunstancias el latín no era el núcleo de la formación de los miembros de la familia real. La educación en la corte, en general, tenía como eje «la formación espiritual y moral» (Val Valdivieso 2013: 11), aunque fuera acompañada de adiestramiento cortesano e instrucción intelectual (Segura Graíño, 2005; Baranda, 2008). Importaba dotar a los príncipes de estrategias de buena conducta cristiana, junto a la atención a cuerpo y mente (Salvador Miguel, 2008). El objetivo de la educación de príncipes y princesas era aprender el oficio de reinar (Pelaz, 2020), para sellar alianzas internacionales y para ser paradigmas de refinamiento cultural y etiqueta cortesana. Describe pormenorizadamente Fernández de Oviedo en el Libro de la Cámara del príncipe don Juan el cuidado de la reina en fomentar las disposiciones de su hijo, la prolijidad y precauciones para que nadie le pudiese distraer de las costumbres.

La monarca eligió una formación por géneros para sus hijos: La vertiente intelectual de esta instrucción fue llevada a cabo fundamentalmente por frailes prestigiosos a los que se unían otros profesores encargados de enseñar otra serie de conocimientos y destrezas, pero organizando el magisterio como un programa formativo colectivo, coral, dentro de las casas reales (Pelaz, 2020). Son muy conocidas las precisas anotaciones contables del tesorero de Isabel la Católica en las que figuran cinco docentes encargados de la instrucción intelectual de los príncipes: El famoso dominico fray Diego de Deza fue el maestro del Príncipe de Asturias desde $1485^{20}$ : para educarle la

20. Torre, 1955, I: 82; 132, 170, 182, 1 94, 231, 282, 322, 393, 412 y 418. Torre, 1956, II: $10,35,41,44,67,88,126,205,263,269,275$ y 564. La cuestión de la educación de los príncipes ha sido bien tratada por otros investigadores, como: Torre, 1956: 256-266. Val Valdivieso, 2011; Val Valdivieso, 2013; Rábade, 2007; Earenfight, 2016; Pelaz 2020... 
reina arbitró una «especie de colegio inventado» cuyos nombres recoge Clemencín (1820: 383); una escuela de «diez caballeros» alumnos nobles, de diversas edades, enseñándose en ella asimismo el adiestramiento militar del maestre Bernal y otros aprendizajes de música, danza o caza (Alcalá y Sanz, 1998: 109; Rábade, 2007: 163 y ss.). Se escribieron obras específicas para su formación ${ }^{21}$.

La educación de las infantas, destinadas a reinas, también debía repartirse entre lo intelectual, lo espiritual y lo cortesano, poniendo el acento en el desarrollo de las cualidades entendidas entonces como mujeres (Val Valdivieso, 3013: 80 y 119; Segura Graíño, 2007: 78). Sin olvidar la preparación para ejercer el arte y las virtudes necesarias para gobernar, el latín y otros idiomas, las princesas debían acostumbrarse a la cultura cortesana, las ceremonias, la administración de las casas reales, el ejercicio de la piedad y el mantenimiento de la memoria dinástica. Sin duda, las hijas de los Reyes Católicos aprovecharon estos principios educativos adaptándose a lo que las circunstancias requerían de ellas: fueron hábiles en el gobierno y en las entretelas cortesanas, ejemplos de piedad cristiana y paradigma de princesas humanistas (Earenfight, 2016).

En la base intelectual de este éxito educativo de las princesas estuvieron: fray Pedro de Ampudia, que figura en 1484 como maestro de la infanta Isabel ${ }^{22}$. Fray Andrés de Miranda, fue desde 1484 «maestro de latín», y después, en distintos años, «maestro de la Ynfante doña Juana» (1486), «maestro de la ynfante doña María» y «maestro de la archiduquesa» ${ }^{23}$. Antonio Giraldino estuvo al cargo de la enseñanza de la infanta Isabel, la primogénita, hasta 1488 en que murió (Clemencín, 1920: 396). Su hermano Alejandre Giraldino fue el maestro de María y Catalina ${ }^{24}$, las únicas princesas que compartieron maestro. El caso de Catalina ha llamado especialmente la

21. Los manuales para la enseñanza de los príncipes representaron siempre un género literario imprescindible. Algunas obras fueron redactadas pensando en los reyes, no en sus hijos: Martín de Córdoba compuso El jardín de las nobles doncellas para contribuir a la educación de la princesa y después reina Isabel la Católica; habla en ella de la condición de la mujer en la sociedad, las buenas y malas tendencias propias de las féminas, aconsejando la elección de personas virtuosas para la convivencia en la corte y el papel de las mujeres en la sociedad y en su relación con el marido, primando la educación espiritual, el ejercicio de la justicia, la franqueza, la concordia y los buenos modales. El mismo autor, en Epístola exhortatoria a las letras, recomienda a la reina que sea buena madre para su reino. Gómez Manrique en el Regimiento de príncipes defendió el ejercicio de la virtud y seguir la senda de la razón. En cuanto a la educación que los reyes debían promover en sus hijos, Alonso Ortiz (Alonso Ortiz. Diálogo sobre la educación del príncipe Juan, hijo de los Reyes Católicos) aboga por la formación espiritual y moral sobre el saber humano. Hubo otros textos coetáneos sobre la educación escritos por Nebrija, Sánchez de Arévalo y otros (Val Valdivieso, 2013: 11-13).

22. Torre, 1955, I: 43, 126, 205, 263, 340, 377 y 431.

23. Torre, 1955, I: 17, 33, 81, 132, 164, 182, 198, 231, 264, 282, 364, 408, 412, 282 у 364. II: $20,44,56,90,126,153,172,205,260,308,339,409,440,507,538,569,609$, y 649.

24. Torre, 1956, II: 56, 120, 125, 206, 263, 340, 378, 412, 420, 455. 
atención de la historiografía (Cahill, 2020). A pesar del prestigio que proporcionaba el oficio, no parece que ser maestro de latinidad de la corte fuera ninguna bicoca; condujo a más frustración que delectación (Jiménez Calvente, 2008).

Marineo explica cómo el interés de la reina por la cultura la llevó a contratar maestros incluso para sus pajes. Él mismo figura durante un tiempo en la contabilidad como profesor de los mozos de coro de la Casa de la Reina (Marineo, 1539: CLXXXII v). Decía Jerónimo Münzer que Pedro Mártir de Anglería educaba a los jóvenes cortesanos enseñándoles a recitar clásicos latinos: «pasan sus horas en el estudio y otros servicios del rey y en la caza, para no perder ni una hora en la ociosidad» (Münzer, H. Itinerarium sine peregrinatio..., cf. Borreguero, 2011: 79). La reina incitó a Nebrija a redactar su gramática latina en castellano para facilitar el aprendizaje de esta lengua a las damas de la corte. El círculo de este programa educativo se cerraba con la creación de las bibliotecas de cada miembro de la familia real y en la elección de una serie de personas, hombres y mujeres, cuya preparación intelectual y ayuda doméstica completaban el ambiente humanista buscado por Isabel la Católica en sus estancias ${ }^{25}$.

\subsection{4. ¿Llegó la reina a aprender latín con Beatriz o con otros?}

Los datos conservados permiten aventurar que Isabel I supo siempre poco latín, aunque valorara su conocimiento.

Fernando del Pulgar escribía a la reina en 1482: «Mucho deseo saber cómo va a Vuestra Alteza con el latín que aprendéis» (Pulgar, $c f$. Gómez de Cibdareal, 1775: 151), luego la reina lo estaba estudiando, pero no debió de progresar en este aprendizaje porque diez años después Marineo anotó:

La qual [reina] (aunque no sabía la lengua latina) holgava en gran manera de oyr oraciones y sermones latinos, porque le parescía cosa muy excelente la habla latina bien pronunciada. A cuya causa, siendo muy deseosa de lo saber, fenescidas las guerras de España (aunque estava en grandes negocios ocupada), començó a oyr lectiones de gramática. En la qual aprovechó tanto, que no solo podía entender [a] los embaxadores y oradores latinos, más pudiera fácilmente interpretar y transferir libros latinos en lengua castellana (Marineo, 1539: CLXXXII v).

25. La biblioteca fue uno de los bienes culturales de la corte. Tempranamente Clemencín estudió los dos inventarios de libros de la reina conservados en el Archivo de Simancas (Clemencín,1820: 434-480). Más información en Díez Garretas, 2008; Cátedra García y Rojo Vega, 2004 («libros de mujeres» más que «bibliotecas de mujeres», pp. 69-108); Martínez Alcorlo, 2017 (biblioteca de la princesa Isabel). 
De estos textos se colige: Primero, que, «o la reina lo estudiaba desde 1480, o lo comenzó a estudiar en 1492, en tanto que la Latina llegó a la corte en $1486 \ldots$ basándose en cualquiera de estos dos testimonios contradictorios se puede concluir que Beatriz no fue a la corte como maestra de latín» (Carabias, 2019: 191).

Y segundo: Que desde Luis Gil en el Panorama social del humanismo español, hay acuerdo historiográfico en la ignorancia generalizada del latín, especialmente entre las mujeres (Sánchez Salor, 2020: 271). Ni las élites lectoras, ni la corte, ni las universidades manejaban con soltura y asiduidad este idioma. Por eso Cuart relativizaba este aprovechamiento de la reina. Recuerda que «el dominio de la lengua latina en España por parte de la gente docta era muy deficiente» en la época de los Reyes Católicos. Así, Cuart pone en duda la opinión de Marineo, obligado como cronista a escribir siempre proezas de sus pagadores (Cuart, 2004: 74).

Es decir, que varios testimonios niegan que la reina llegara a dominar el latín y que Beatriz fuera a la corte como maestra. Cristina Segura ha concluido en su último estudio: «Se ha insistido que fue preceptora de las hijas de Isabel la Católica, pero parece que su magisterio se limitó a las conversaciones en latín con la Reina» (Segura Graíño, s.a.). Lo que es indudable es que la monarca tuvo gran interés por la lengua del Lacio y que se rodeó de puellae doctae o «mujeres sabias» - se desconoce hasta qué punto lo eran - entre las que se incluye a Juana de Contreras, Isabel de Vergara - a la que el propio Marineo Sículo calificó de latine graeceque doctissima, luego le merecía mayor admiración que la Latina-, Florencia Pinar, Magdalena de Bobadilla, Catalina de Medrano - hermana de Luisa de Medrano-, María Pacheco - mujer del comunero Juan Padilla, de quien Marineo dice que conversaba sobre cuestiones «del saber» (Val Valdivieso, 2006a) - y «la puella docta más famosa de esta época» -según Rivera Garretas -: Beatriz Galindo (Rivera Garretas, 1997:125). La reina las atrajo a sus estancias y se preocupó de que la corte al completo estudiara latín (Val Valdivieso, 2011: 270) y otras habilidades cortesanas, como: «Leer, escribir, tañer, cantar, danzar, nadar, luchar esgrimir, arco, ballesta, llatinar e decir, xedrez y pelota saber bien jugar», como decía Juan de Lucena.

\subsection{5. ¿Fue universitaria Beatriz? ¿Fue una gran humanista y la única latina?}

Oettel (1935) realizó la primera investigación seria que defendió la presencia de mujeres en la universidad castellana del Renacimiento. El estudio documental que ofreció fue muy minucioso para el caso de Luisa de Medrano. Recuerda que Marineo Sículo y Pedro de Torres la escucharon leer públicamente en el Estudio de Salamanca; el primero ensalzó sus conocimientos y Torres recordó en su Cronicón su lectura en el aula de cánones de la Universidad de Salamanca. Oettel concluyó su ensayo suponiendo que Luisa habría impartido docencia sobre los clásicos, o quizá sustituyendo a Nebrija en la cátedra de gramática de la Salmantina (Oettel, 1935; más información en Mateos Díaz, 2019). 
La obra de Oettel tuvo y tiene un impacto impresionante en la historiografía de género. Siguiendo su estela, se ha afirmado, sin datos documentales ciertos, la presencia de mujeres en las universidades del Renacimiento: Beatriz habría sido alumna en Salamanca según Val Valdivieso (2003: 32), Borreguero Beltrán (2011: 15), Martínez Alcorlo (2020: en línea), Guil Bozal y Flecha García (2015: 129), entre otros. Medrano y Juana Contreras habrían sido profesoras «de Humanidades y, probablemente también de Derecho» en la Universidad de Salamanca (Borreguero, 2011: 85). Francisca de Nebrija, hija del famoso gramático, le «sustituyó en la cátedra de Retórica de Alcalá» (Borreguero, 2011: 85). Beatriz Galindo, «a los dieciséis años parece que dominaba esta lengua [latina] de tal manera que asombró al claustro de la Universidad Salmantina» (Segura Graíño, s.a.). Pues bien: Es inverosímil que una mujer pudiera asistir a una reunión del claustro universitario salmantino, al que ni siquiera tenían acceso todos los matriculados, sino a través de representantes; además, en las reuniones de claustro jamás encontré una disertación de nadie, y he leído cientos de actas de ellos. A día de hoy no hay datos que permitan demostrar ninguna de estas afirmaciones. Cuando alguna mujer dejó escrito que asistió al Estudio salmantino, habría que saber a cuál, porque hubo varios estudios en esta ciudad y en esa época. Las universidades eran centros de estudio masculinos, donde cabe la excepcionalidad de que una mujer o varias ofrecieran una presentación pública de un tema, a pesar de que los estatutos de la Universidad de Salamanca y las constituciones de los colegios universitarios conminaban a los estudiantes a no tratar siquiera con mujeres (de ahí quizá la incidencia de la homosexualidad entre ellos). Me encantaría que alguien pudiera demostrar lo contrario...

Por lo que se refiere a la consideración de Beatriz como «humanista», también tiene larga tradición, desde los estudios de Rivera Garretas (1997), Arroyal et al. (2006), Segura (2011), Belda (2013), Caso (2019)... hasta Sánchez Salor (2020) sigue definiéndose su condición de "gran humanista», pero nadie argumenta con datos ciertos el porqué de esta atribución.

Tomemos como ejemplo lo que indica Rivera Garretas cuando dice que de su obra literaria «quedan referencias, al parecer inseguras, a títulos: Notas y comentarios sobre Aristóteles y Anotaciones sobre escritores clásicos antignos. Se dice también que escribió poesía en latín». Rivera dice tomar estos datos de autores como Aurea Martín Tordesillas, Diego Ignacio Parada, Serrano Sanz o Margarita Nelken, que a su vez las recogieron de forma imprecisa de otros anteriores (Rivera Garretas, 1977: 126).

Aprender latín o música era habitual entre las niñas y jóvenes que aspiraban con ello a optar a una rebaja o anulación de la dote para ingresar en la vida conventual. Sabemos con certeza que Beatriz estudió latín de niña con este objetivo - lo hemos recordado ya- y, dentro de los ejercicios habituales de este aprendizaje, es seguro que haría algún ensayo sobre Aristóteles o sobre cualquier otro autor clásico, pero no ha quedado noticia cierta de ninguno de estos trabajos, ni de poesía alguna. Rivera

Ediciones Universidad de Salamanca / 요 Stud. his., H. ${ }^{a}$ mod., 43, n. 2 (2021), pp. 71-104 
Garretas, Martín Tordesillas, Sanz, Nelken y los demás, con la mejor intención, están difundiendo una información imposible de corroborar y de la que no hay ni rastro en la documentación.

Ante la inconsistencia de las noticias que se han venido asumiendo como ciertas por repetición, Pedro Porras concluyó su análisis biográfico de la Latina diciendo que «no contamos con casi ninguna información acerca de la actividad intelectual de Beatriz sobre las obras que pudo escribir o sobre la profundidad de sus conocimientos clásicos. Dicho de otro modo, no sabemos si era simplemente una señora que podía expresarse en términos latinos o si, por el contrario, era una persona imbuida del universo renacentista» (Porras, 2006: 261).

Por otra parte, se reconocía con el sobrenombre de «Latina» a cualquier joven que supiera latín. Así se desprende de la carta de Isabel la Católica a Sepúlveda, donde la reina se refiere a su hija como «la Latina» (cf. Beltrán, 1971, III: 307), residente en Salamanca. Beatriz, no era, pues, la única latina de Salamanca ¿Llamarían en la corte «Latina» a Beatriz como forma de distinguirla entre las cuatro criadas con el mismo nombre y oficio: Beatriz de Paredes, Beatriz Gómez, Beatriz Marque y Beatriz Galindo? En realidad justamente eso es lo que dice Marineo de ella, cuando hemos dicho que expresó:

...et propter linguam latinam, qua maxime pollebat, latina fuit cognominata (Marineo Sículo, 1530a: CLXXIV v).

...y, por la lengua latina que hablaba sueltamente, fue dicha por sobrenombre la latina (Marineo Sículo, 1530b: CCLII v).

En este encomio de Marineo a la Latina solo le atribuye la dicción fluida del latín. Obsérvese la gran diferencia con lo que dice, en la misma obra, de Isabel de Vergara (a la que califica como latine graeceque doctissima), o sobre María Padilla, de quien dijo que conversaba sobre cuestiones «del saber».

Teniendo esto en cuenta, cabe concluir, como Porras y Segura Graíño, que la fama de Beatriz «es mucho mayor que las informaciones fidedignas» (Segura Graíño, s.a.). Ha sido una notoriedad amplificada por la historiografía.

\subsection{Beatriz Galindo: de criada a señora. El encumbramiento de una familia entera}

A pesar de haber nacido en una sociedad estática, Beatriz Galindo es un paradigma del proceso de ascenso social a través de la cultura y el matrimonio.

Como decía Hespanha, en la sociedad castellana de ese tiempo el cambio ni se esperaba ni se deseaba. Primaba el concepto de orden, en la Tierra y en el cielo, acorde con la idea religiosa de la Creación, con el estado natural (Hespanha, 2006: 21 y ss.). La movilidad social no estaba bien vista, sobre todo por la Iglesia, ya que 
su misión era garantizar la salvación de todos, manteniendo el orden en este mundo; es decir, haciendo que cada uno aceptara con resignación cristiana el lugar que le había sido asignado por Dios (Castellano, 2007: 5-18). Por designio divino había nobles y plebeyos. Se atribuían a la nobleza natural algunas cualidades espirituales (derivadas de la virtud) que se adquirían a través de la sangre, y ahora también a través de la cultura.

A pesar de ello, en la sociedad castellana se produjo un «cambio inmóvil» (Soria Mesa, 2000: 169-170) y, desde el último cuarto del siglo XV, los castellanos tuvieron excepcionalmente a su alcance cinco vías de promoción social que pasaban por la Iglesia, la corte, la universidad, la «gracia» (real o pontificia) y el ejército (Carabias, 2012a: $15-21)^{26}$. La prosperidad de la familia de Beatriz comenzó con la admisión de ella misma como criada de la reina, continuó con la promoción de su hermano, Gaspar de Grizio, como secretario del príncipe don Juan y, después de la temprana e inesperada muerte de este, de los propios reyes, y tuvo el camino expedito con su matrimonio con quien sería general de artillería, secretario real y miembro del Consejo Real, aparte de otros oficios administrativos y municipales en distintos lugares. Los Ramírez-Galindo «medraron» en la corte, que es lo que hacía - según explicaba Covarrubias - , el que «va procediendo de mal a bien, o de bien en mejor» (Covarrubias, 1611: 1088,1). La proximidad a la monarquía activaba los mecanismos de privilegio y merced (Muñoz Fernández, 2000).

La reina ejerció sobre Beatriz la patria potestad buscándole marido y dotándola, como hizo con el resto de las doncellas de su corte. Era costumbre conocida. Hernando del Pulgar escribió que la reina dotaba espléndidamente a las mujeres de su corte, «e fazíales grandes merçedes por las casar bien» ( $c f$. Fernández de Córdoba, 2002: 160). Lo mismo dijo Marineo: «Tenía [la reina Isabel] consigo muchas damas nobles de linaje y señaladas en virtud y gran número de doncellas... después de crecidas las casaba y con ricos [sic] dotes honradamente» (Marineo, 1539: CLXXXII v). Era este un procedimiento habitual en la corte de los Trastámara; volveremos sobre ello.

El elegido para esposo de la Latina fue el hidalgo y segundón Francisco Ramírez ${ }^{27}$, el Artillero (c. 1445-1501), ya viudo de Isabel de Oviedo, de la que le quedaron seis hijos. Quienes hablan de él «han oscilado desde el canto laudatorio a sus gestas

26. Estas nuevas y efectivas vías de ascenso social se rarificaron a medida que avanzó el siglo XVI. Recordemos que fue una movilidad «dramática», muy rápida, tanto ascendente como descendente (Marcos Martín, 2007: 19-48).

27. Varios historiadores atribuyen la hidalguía Ramírez. Me permito dudarlo porque, si así fuera, no tendría ningún sentido la concesión de la nobleza que el rey otorgó graciosamente a Beatriz y a su familia tras el fallecimiento de aquel (volveremos sobre ello). Ya serían nobles, y no conozco otro caso en el que a una persona que disfrutara de la condición de nobleza se le otorgara de nuevo. 
y a su generosidad o religiosidad, hasta los que le han sorprendido profiriendo amenazas o intentando conseguir bienes rústicos a bajo precio bajo coacciones» (Porras, 1996: 16) ${ }^{28}$.

Ramírez, en su primer matrimonio había emparentado con el linaje de Juan de Oviedo, repostero y secretario de Enrique IV, y después de Isabel I; el Artillero suplantó a los Oviedo «al adjudicarse sus bienes como esposo de Isabel de Oviedo e, incluso, sus cargos, como secretario real o regidor de Madrid» (Porras, 1996:1516; Bermejo, 1979: 202 ss.); y fue el «verdadero organizador y comandante de la artillería real durante la conquista de Granada» ${ }^{29}$.

Pedro Porras estudió con precisión la relación económica que derivó del compromiso matrimonial con Beatriz ${ }^{30}$ y las circunstancias económicas en las que quedó la viuda tras el fallecimiento de el Artillero (Porras, 2006), que aquí resumo: El 26 de febrero de 1491 la reina obligó (subráyese esto) al Artillero a firmar la escritura de recepción de la dote de 500000 maravedís y este prometió a Beatriz, en arras, el diezmo de su fortuna (1000 florines de Aragón, o sea 265000 maravedís) «por su crianza, linaje y virginidad ${ }^{31}$, la obligación de mejora a la esposa y a los posibles futuros hijos del matrimonio ${ }^{32}$, y el compromiso de entregarle 50000 maravedís anuales si no tuviese descendencia ${ }^{33}$. El 20 de diciembre de 1491, en vísperas de la boda - que probablemente se celebró en la Navidad-, en Santa Fe (Granada), Beatriz recibió de manos de la reina 400000 maravedís para vestuario y ayuda al casamiento. Ese mismo día la monarca también ordenó entregarle 42000 maravedís, importe de cuarenta varas de terciopelo grana (Torre, 1957, II: 258). Obsérvese que hemos utilizado expresiones de obligación, porque sabemos que la reina forzó un matrimonio que al menos no era deseado por el que iba a ser el novio.

28. Se conoce bastante de la biografía del Artillero: Porras,1995; Porras, 1996; Porras, 2006 (en la biografía de la Latina hay asimismo datos de Ramírez); Porras, s.a.; Huidobre, 2017.

29. Información sobre su crecimiento patrimonial y oficios en Porras, 1996: 17; Porras, s.a. Sobre la importante participación del Artillero en la Guerra de Granada: Ladero, 1976: 56 y $121-123$.

30. Capitulaciones matrimoniales. AHNobleza, Bornos,C.433,D.1; Bornos,C.459,D.3. Más información en Porras, 2006.

31. AHNobleza, Bornos,C.433,D.1.

32. Escritura de obligación en Sevilla a 26 de febrero de 1491 por la que Francisco se obliga a mejorar un tercio las rentas de su mujer si tuviera hijos. AHNobleza, Bornos, C.459,D.3

33. AHNobleza, Bornos, C.459,D.3. AHNobleza (Toledo), Bornos, leg. 1599, cf. Porras, 1996:186-187. El primogénito del primer matrimonio de el Artillero, Juan Ramírez, recibió con enorme enfado la noticia del nuevo enlace matrimonial de su padre, porque ello suponía una más que probable quiebra en su herencia. La reina se encargó de que el Artillero firmara los compromisos matrimoniales que ella decidió. Con posterioridad, los hijos del primer matrimonio se vieron obligados a renunciar a las legítimas en favor de Beatriz, cosa llamativa (Escrituras de renuncia de las legítimas paterna y materna de los hijos de Ramírez y su primera mujer, en favor de Beatriz Galindo. AHNobleza, Bornos,C.45,D.1). 
De este modo, la criada de unos 26 años, de origen humilde, que había necesitado limosnas incluso para vestirse, se convirtió en la rica consorte de un hombre viejo para la época, cercano a la cincuentena. En este matrimonio, y muy especialmente en su viudez posterior, está la clave del encumbramiento social de la Latina y de la fama que ha tenido en la historiografía.

El primogénito de sus dos hijos varones nació el 24 de agosto de 1492, recibiendo el nombre de «Fernán», como su padrino de bautizo, el rey Fernando. Porras advierte que entre el enlace matrimonial y el nacimiento pasaron ocho meses y cree en la posibilidad de que dicho matrimonio,

...forzado por la Reina, fuera de conveniencia, para cubrir una infidelidad de su esposo con su criada, como se maliciaba Llanos y Torriglia; de modo que el primogénito de Beatriz fuera, en realidad, hijo del Rey Católico. Los comportamientos posteriores del monarca, de la Latina y del infortunado Fernando Ramírez así parecen avalarlo... nada extraordinario para las costumbres de la época ${ }^{34}$.

Si realmente fue ese el origen del concierto matrimonial de la Latina, no representó novedad destacable en las costumbres cortesanas del tiempo. Marineo, que de ninguna manera se atrevería a levantar un falso testimonio sobre la usanza de sus jefes, los reyes, decía:

[La reina] amaba en tal manera el rey, su marido, que andaba sobre aviso con celos... a ver si él amaba a otra, y si sentía que miraba a alguna dama de su casa con señal de amores, con mucha prudencia buscaba medios y maneras con que despedir a aquella tal persona de su casa, con su mucha honra y provecho (De Rebus... cf. Llanos, 1920: 25. Porras, 2006: 253).

La excelente armonía que existía entre las personas de los Reyes Católicos en el terreno político trocaba en inseguridad personal de la reina «que a su vez revelaba una pasión por su marido que iba más allá de lo que cabía esperar de un matrimonio de conveniencia» (Tremlett, 2017: s.p.).

La vida siguió de momento casi siempre fuera de la corte para los recién casados. Tuvieron dos hijos, el citado Fernando, primogénito, y Nuflo, el segundo ${ }^{35}$. Lo cierto es que los actos del Artillero en las campañas militares de Andalucía fueron esforzados, asombrosos (cuando se considera el relato histórico de las fuentes

34. Llanos y Torriglia sugiere que el rey andaba en amores con Beatriz y con otras. Tuvo varios hijos ilegítimos.

35. Hay quien alude además a alguna hija del matrimonio, de la que no hay rastro en la documentación consultada. 
documentales que los recogen ${ }^{36}$ ) y muy valorados por los reyes que, como parte del botín de guerra, defendieron el expolio de las tierras del Reino de Granada, del que se beneficiaron el Artillero y otros artilleros y jefes militares de la contienda. El patrimonio que acumuló en poco tiempo el esposo de Beatriz fue muy relevante; sus bienes

...serán particularmente importantes en Madrid (su cercado de Atocha sería expropiado en el siglo pasado para la construcción de la estación del ferrocarril de Aranjuez y su soto y molinos de Mohed serían el centro de recreo de las cortes borbónicas, siendo retratados por Francisco de Goya como la Pradera de San Isidro, por solo citar dos ejemplos), Jaén, Granada, Motril, Écija o Málaga (Porras, 2006: 235).

En el verano de 1496, como unos cortesanos más, la criada - que no había dejado de serlo a pesar del matrimonio, según veremos- y el Artillero despidieron en Laredo a la princesa Juana en su viaje a Flandes. Pero el 17 o 18 de marzo de 1501 murió Francisco en acto de servicio, peleando contra los moros en Sierra Bermeja, Málaga. Tras enviudar, Beatriz vivió dos circunstancias dispares: Por una parte recibió de los reyes «un aluvión de documentos favorables a sus intereses» y a los de sus hijos: avocación ante el Consejo Real de todas las causas (quien quisiera enfrentarse judicialmente a ella debía hacerlo en la corte, ante el rey; orden inusual); adjudicación a la viuda de todos los bienes gananciales, dote y arras; condonación de todas las deudas del difunto con la hacienda regia (1501); el 5 de julio de 1502 concesión de la hidalguía a todos los miembros de la familia; el nombramiento del primogénito como alcaide de la fortaleza de El Pardo (1503) y de Salobreña (1504) con salario de 250000 maravedís anuales (por tanto, con la dignidad y el sueldo de su padre) (Porras, 1995: 174) y el título de comendador de la Orden de Santiago (Porras, 2006: 256-257). Tantas distinciones y prebendas sobre el primogénito, que en ese momento solo tenía ocho años (y no sobre el segundón), caminan en la dirección de la sospecha de que el padre biológico del mismo fuera el propio rey Fernando.

También avalan esta hipótesis los estudios de antroponímia. El mismo año en el que nacía el primogénito de Galindo (1492), el rey Fernando apadrinó a dos conversos y ambos recibieron por nombre el mismo que el vástago de la Latina: «Hernan»; los conversos fueron respectivamente Hernán Núñez Coronel y Hernán Pérez Coronel. Joseph Pérez alerta al respecto: «nótense los nombres de pila: en ambos casos son los mismos que el rey, su padrino» (Pérez, 2005: 190). No podemos

36. Cruces Blanco ha estudiado la trayectoria militar del Artillero como base de su promoción social (Cruces, 1997). Desde el inicio de la Guerra de Granada en 1482, participó en la batalla de Lucena, la recuperación de Zahara, las campañas de Alora, Seternil, Ronda, Cambril, Loja, Illora, Moclín, Vélez-Málaga y Málaga, Baza y la gesta de Salobreña hasta las capitulaciones de Santa Fe, y la sublevación de Sierra Bermeja en la que el Artillero encontró la muerte (Porras, 1996: 101-254). 
olvidar que la elección del nombre «rara vez es inocente o gratuita, especialmente cuando esta se produce en contextos determinados, en géneros o épocas en las que existe un código, un modelo o una estructura muy marcados» (Coduras, 2015: 9 y 235), que es justo lo que ocurría en ese momento y lugar.

La viuda, a pesar de que tuvo el apoyo de Fernando el Católico a sus puntos de vista $^{37}$, se enfrentó ácidamente a multitud de pleitos (Arroyal et al, 2006: 308-311; Porras, 2006). Litigó contra la validez del testamento de su marido cuyo contenido conoció tras enviudar: contradijo judicialmente los mayorazgos de sus hijos fundados por el Artillero en ese mismo testamento, a los cuales se enlazaban bienes con notables diferencias a favor del primogénito, y a los que el finado vinculaba injustamente haberes de su esposa, eliminando de la posible sucesión en el mayorazgo a todos los familiares de Beatriz ${ }^{38}$.

Es verdad que el Artillero dejaba a Beatriz el usufructo de la hacienda vinculada en tales mayorazgos, pero, bajo el amparo regio, la Latina tomó entonces inmuebles de ese mayorazgo para fundar el hospital, dejando a su hijo mayor sin casa en la que residir en Madrid, lo que provocó una violenta reacción de este. De la gravedad de los enfrentamientos entre la madre y el hijo da cuenta una orden del rey prohibiendo la entrada de Fernando Galindo Ramírez en los inmuebles de la Latina. El mandato no tiene desperdicio y por eso lo reproducimos:

37. Este apoyo regio fue absoluto en el comienzo de la viudez de Beatriz y, no solo se reflejó en la dotación de mercedes, privilegios, cargos y oficios para ella y sus hijos, sino que llegó a todas las facetas de la vida de antigua criada. Por ejemplo, el proyecto de creación del primer convento, de advocación no definida en origen, generó protestas por parte de los frailes, y el rey ordenó al Comendador de Santa Catalina de Toledo, que se abstuviera de intervenir, porque el monasterio que Beatriz edifica en Madrid es de exclusiva incumbencia real (Segovia, 9 de julio de 1505; AGS,CCA,10,f.110v). Sin embargo, la Latina sufrió el desencanto de la pérdida progresiva de este favor: A pesar de que Carlos I acudió a visitarla cuando vino de Flandes, lo cual representa un gran honor y consideración (la influencia del rey Fernando estaba aún reciente), en 1519 la arrebató la tenencia de la alcaidía de El Pardo detentada por el comendador Ramírez, y, tras un tiempo de disputa, se le adjudicó al favorito del rey, Adrián de Croy. Parece que Beatriz luchó cuanto pudo por mantener el predicamento del monarca y, en 1523 prestó medio millón de maravedís al rey para paliar el apuro económico que este tuvo en el cerco de Fuenterrabía. Sin embargo, la sintonía con la Casa Real quedó rota en 1529, cuando la emperatriz Isabel se quejaba por escrito de que algunas personas la importunaban pidiéndole la escribanía mayor de rentas de la Orden de Santiago, vacante por fallecimiento del primogénito de la Latina: La importunadora era Beatriz (Porras, 2006: 259).

38. Facultad otorgada por los Reyes Católicos al secretario Francisco Ramírez de Madrid para instituir mayorazgos para sus hijos, 22 de mayo de 1499 (AGS, RGS,leg.,149905,4). Tras el recurso judicial de la Latina contra estas cláusulas recogidas en el testamento de el Artillero, no sabemos si estos u otros mayorazgos distintos son los que finalmente disfrutaron los dos niños (desde 1504). 
El Rey. Fernán Ramírez vecino y regidor de la villa de Madrid. Yo he sabido que vos habéis intentado muchas veces de entrar por fuerza contra voluntad de Beatriz Galindo, vuestra madre, en las casas que ella tiene fechas junto con su hospital, y que tratáis mal las cosas del dicho hospital y a las personas que sirven en él... por la presente vos mando que vos ni otra persona ni personas algunas por vos, no entréis ni estéis en el dicho hospital contra voluntad de la dicha vuestra madre, so pena de cien mil maravedís para la mi cámara e de ser desterrado de la dicha villa cuanto mi merced y voluntad fuese... Burgos, 6 de marzo de 1502 (cf. Llanos, 1920:78-79; Beltrán, III, 1971: doc. 997, 308).

El contenido de este documento impresiona, y llega a sobrecoger si tenemos en cuenta que el hijo de Beatriz tenía entonces nueve años. Ante estas disensiones, al alcanzar el primogénito cierta edad, llegó a un acuerdo con la madre para recibir la posesión de estos bienes a cambio de una renta anual, convenio que pronto incumplió el joven, llevando a la madre a disolver el pacto en 1511, acusándole de desobediente y derrochador. La demanda que puso entonces el hijo, Fernando, contra su madre se resolvió en un año con la intervención de la reina Juana, que ratificó la atribución a la Latina de todos los bienes de Fernando, perpetuando el enfrentamiento familiar. La muerte de este hijo en 1529 (y la previa de su segundo hijo, Nuflo, en 1525 o 1526) zanjó temporalmente esta larga y escabrosa disputa, que continuarían judicialmente sus nueras.

El hecho de que la Latina no conociera el texto del testamento del Artillero antes de su muerte, su disconformidad con su contenido, los pleitos que interpuso contra varias cláusulas del mismo, y la retirada de la custodia legal de sus hijos a través de ese mismo testamento, parecen hablar de una pésima relación personal entre los desposados. Importa recordar que la Latina no fue por mucho tiempo la curadora de sus propios hijos después de enviudar, pues, tras las sentencias judiciales, quedaron legalmente al cargo de su hermano, Gaspar de Gricio, trapisondista de pro con los dineros ajenos ${ }^{39}$, designado tutor de los niños por el finado ¡Las diferencias entre la Latina y su esposo debieron ser morrocotudas, para que el padre quitara la patria potestad de los hijos a la madre, y para que esta se enterara del hecho en la lectura del testamento del difunto! Esta situación permite suponer que las relaciones personales entre Gricio y su hermana tampoco debían ser edificantes.

39. Gaspar de Gricio fue denunciado como secretario real por cobrar aranceles abusivos. La partición de los bienes del testamento de Francisco Ramírez se hizo a instancias de Gricio, como curador de los menores de su hermana Galindo (Porras, 2006: 254 y 256). Recordemos que, en febrero de 1504, los monarcas habían confirmado al hijo primogénito de Beatriz, Fernando, como alcaide de Salobreña - oficio antes ocupado por su padre-, recibiendo por ello 250000 maravedís anuales (Porras, 1995: 174, nota 17), dinero que, como niño de diez años, administraría también su curador. Quedarse al cargo de esos niños conllevaba una nada desdeñable recompensa económica hasta que ellos adquirieran la mayoría de edad.

Ediciones Universidad de Salamanca / అ@@ Stud. his., H. ${ }^{a}$ mod., 43, n. 2 (2021), pp. 71-104 
Beatriz se implicó asimismo en varios litigios con los administradores de sus señoríos y contra el guardián del Convento de San Francisco el Grande. La Latina resultó litigante por naturaleza hasta su óbito, el 23 de noviembre de 1535.

Antes y después de la muerte de su marido Beatriz continuó figurando como sirvienta doméstica de la Casa de la Reina y el tesorero le pagó casi regularmente, hasta 1504, los 15000 maravedís de quitación, ayuda de costa y vestuario, como a cualquiera de las criadas realmente afincadas en la corte ${ }^{40}$. Por encima de estos ingresos, ella disfrutaba de un juro de 100000 maravedís sobre las alcabalas de las tierras de Madrid y de Talamanca que le había otorgado el rey en 1497, cobraba las rentas vitalicias del portazgo de Carrión, gozaba de otro juro de 100000 maravedís para ayuda de costa y un juro nuevo, de 70000 maravedís, sobre las rentas de Madrid y Talamanca, en recompensa por el préstamo de 1200000 maravedís que la Latina había hecho al rey para los gastos atrasados de la guerra (AHNobleza, Bornos, leg. 1537) (Porras, 1996: 216-217 y 223). Beatriz era tan rica como para prestar dinero al propio rey.

A pesar de ser, como vemos, una viuda rica y poderosa, incomprensiblemente, el tesorero real efectuó varios pagos a su favor como jornal por haber trasladado enseres domésticos en acémilas de unas villas a otras ${ }^{41}$. Resulta cuando menos sorprendente que Galindo recibiera tan solo 146,6 maravedís ${ }^{42}$ diarios en marzo de 1504 por este encargo, cuando, aparte de las rentas antedichas, al enviudar, por orden real se le concedió la adjudicación de todos los bienes gananciales, dote y arras, cuando seguía recibiendo el sueldo como criada (15000 maravedís anuales; 41 maravedís diarios) y cuando, además, disfrutaba de sustanciosísimas sumas de dinero recibidas regularmente de los administradores del inmenso patrimonio inmobiliario amasado por su esposo ahora difunto.

No hay rastro de ningún otro pago a Beatriz como arriera durante los años previos a su matrimonio en los que trabajó como moza en la corte, y choca que realizara esas duras faenas cuando económicamente ella hubiera podido pagar sobradamente a terceros para llevarlas a cabo ¿A Acaso ese tipo de trabajos fueron una forma de desquite de la reina frente a la infidelidad de la ahora rica criada con

40. Torre, 1956 II: 380, 414, 458, 514, 574, 616 y 659 .

41. El 23 de abril de 1496, se le encargó trasladar «la recámara de su Alteza e del archiduquesa e infantes...» en «dos azémilas que vinieron con Beatriz Galindo, jornal de 14 días e medio, 101 sueldos e tres dineros». El 12 de marzo de 1504 el tesorero le pagó «por tres acémilas que traxo Beatriz Galindo desde Segovia a Medina, por 3 días, al precio de 440 maravedís» (Torre, 1955, I: 333 y 625).

42. Según la equivalencia de monedas establecida por Eloy Benito Ruano en el libro del limosnero de Isabel la Católica (Benito, 2004: 18), 1 sueldo tenía el valor 18 maravedís; 1 dinero equivalía a 1,5 maravedís. Así pues, el jornal que recibió del primer encargo fue de 125,6 maravedís al día; y del segundo de 146,6 maravedís diarios. 
su marido, el rey? ¿Mantuvieron siempre la reina y Beatriz la idílica relación que se lee en Marineo, Fernández de Oviedo y en otras crónicas?

A pesar de lo expuesto, la mayoría de los historiadores que hablaron de Beatriz hasta el siglo XX ofrecieron una visión muy sesgada del personaje y todos, sin distinción, lo hicieron en tono laudatorio: nunca se ha recordado su trabajo como criada doméstica; apenas se habla de los ácidos e innumerables pleitos y públicas desavenencias que arrastró hasta su muerte. Siempre se la describe como una mujer valiosa, culta, inteligente, honesta, piadosa hasta la santidad (se recuerdan las premoniciones sobre el incendio del hospital y otros, e incluso algún milagro por su intercesión) y cercana a la monarquía; también como una gran amiga de la reina (Pérez Samper: 628). De lo que no cabe duda es de que fue muy amiga del rey. Un ejemplo de lo que digo es lo que escribió Alonso de Santa Cruz (1505-1567), en 1542:

...[Beatriz] era muy privada dellos [los reyes] y con quien la Reina Católica descargaba su conciencia. Y con mucha razón: porque dexado que hera cristianísima mujer, hera tan sabia y tan avisada, que también parecía averse criado con una Reina [la Virgen] en quien toda la virtud y bondad y saber del mundo estaba (Santa Cruz, 1951: 243-244).

Hemos visto que Fernández de Oviedo incluyó a la parentela Ramírez-Galindo entre los personajes «ilustres» de sus Batallas y quinquagenas, donde se explayó en noticias sobre reyes y nobles. Ahora sabemos que el cronista podía tener interés personal en subrayar la relevancia del Artillero y de la Latina, porque estaba «directamente emparentado con ellos» (Porras, 1996: 13): La primera esposa de Francisco Ramírez era una Oviedo: airear los méritos de Francisco Ramírez y de su familia, verdaderos o acrecentados, era buena contribución al encumbramiento de su propio linaje.

Sin duda se logró, y de los hijos de Francisco y Beatriz derivaron varios linajes nobiliarios: De Fernando procede el condado de Bornos, y de Nuflo, su segundón, el ducado de Rivas. A estos se unirán después los condados de Murillo, Villariezo, Guevara, marquesado de Villanueva de Duero...; títulos que en parte llegan hasta hoy en Fernando Ramírez de Haro Valdés, conde de Bornos y Grande de España, esposo de Esperanza Aguirre, padres de Fernando (marqués de Villanueva de Duero, con Grandeza de España) y de Álvaro (marqués de Villariezo) ${ }^{43}$.

Observamos, pues, que Beatriz Galindo siguió el patrón de elevación social de otras criadas de la corte. Paradigmático puede ser, en este sentido, el caso de Beatriz de Bobadilla, marquesa de Moya (c. 1440-1511): fue nombrada por Enrique IV como doncella y criada de su hermanastra (la futura Isabel la Católica), y casada por

43. Un estudio de la línea familiar desde el siglo XV hasta el presente puede verse en Carabias (2012b: 143-238). 
este monarca con su mayordomo, Andrés Cabrera, recibiendo por su matrimonio «varias mercedes que constituyeron el punto de partida de su irresistible ascenso social» (Morales Muñiz, s.a.). Esta promoción fue exponencial tras el apoyo del matrimonio a la causa de Isabel y Fernando, hasta llegar a detentar el extraordinario privilegio de ser quien cierre los ojos a la reina fallecida. Así pues, estamos ante un patrón cortesano de promoción social: de criada a señora; de señora a noble con capacidad de empoderamiento a través de un alto rango económico y cultural (modo de vida, costumbres, conocimientos, desarrollo artístico, mecenazgo...). Como toda dama noble que se preciara, la marquesa de Moya, junto a su marido, fundaron el convento de Nuestra Señora de Tejeda. Aunque la Latina alcanzó un rango social inferior al de Bobadilla, el paralelismo vital es significativo.

\section{REFLEXIONES FINALES}

Este trabajo se enmarca en la línea historiográfica que pretende rebajar las expectativas abiertas en anteriores estudios de género sobre las mujeres sabias del Renacimiento español. Martín Baños demostró que Francisca de Nebrija, la supuesta hija que le habría sustituido en la docencia de la cátedra de la Universidad de Alcalá de Henares y que hoy intitula el Premio «Francisca de Nebrija» de esa institución, en realidad nunca ha existido (Martín Baños, 2019: 448 y 449). Mateos (2019 y otro estudio en prensa) y yo misma (Carabias, 2019) hemos evidenciado que Luisa (llamada Lucía por error) de Medrano nunca fue catedrática de una universidad. La presente investigación, junto a los estudios de Torre (1957), Porras (2006), Rábade (2016) y Carabias (2019) han puesto de manifiesto la sobrevaloración de la figura de la Latina y han ofrecido datos que reclaman la «desmitificación de la aureola del personaje llegada hasta nosotros» (Porras, 2006, 258).

La conclusión fundamental de este estudio es la ratificación de que Beatriz nunca fue maestra ni de la reina ni de sus hijas: esto me parece incuestionable; pero su destreza latina le abrió las puertas de un trabajo doméstico en la corte, lo que en sí mismo ya suponía una notable promoción personal para una jovencita de origen pobre.

La liberalidad y el talante limosnero de la monarca, así como la «gracia real» que representaba la costumbre de Isabel de ejercer la patria potestad con sus criadas doncellas, la condujo a un matrimonio económica y socialmente muy ventajoso para la Latina. Este matrimonio «forzado por la reina» con el viudo Francisco Ramírez ha despertado la sospecha de que el padre de Fernando Ramírez Galindo pudiera haber sido el rey Fernando, a juzgar por las mercedes y el trato privilegiado que la monarquía otorgó a este niño (no al otro) y a su madre cuando Beatriz enviudó tras nueve años de matrimonio. El rey pidió consejo y ayuda económica a la viuda en varias ocasiones y, de hecho, la antigua criada prestó nada menos que 1200000

Ediciones Universidad de Salamanca / 요 Stud. his., H. ${ }^{a}$ mod., 43, n. 2 (2021), pp. 71-104 
ANA MARÍA CARABIAS TORRES

LOS PROBLEMAS DE INTERPRETACIÓN DE LAS FUENTES DOCUMENTALES

SOBRE BEATRIZ GALINDO, LA LATINA

maravedís a Fernando el Católico y 500000 maravedís a Carlos I, acuciados ambos, en distintos momentos, por las necesidades económicas de la guerra.

El Artillero logró mayores y más abundantes méritos administrativos y militares para ser recordado que Beatriz, pero paradójicamente la fama se la llevó la Latina, probablemente porque supo administrar mejor los bienes del finado en beneficio de su propio nombre, colocándolo a la cabeza de importantes fundaciones en Madrid con las que deseó hacer perdurar su memoria: el Hospital de la Concepción de la Madre de Dios y los conventos de la Concepción Jerónima y de la Concepción Francisca. En la gestión y dotación de estas fundaciones, y en la inmensa fortuna económica que llegó a acumular, está el origen de la fama que adquirió Beatriz y el germen del futuro encumbramiento familiar.

Así pues, el dinero y los cuantiosos bienes materiales derivados del ejercicio de los oficios y de los botines de guerra que la herencia de su esposo le proporcionaron, fueron la base de su encumbramiento socioeconómico (Cruces, 1997); como toda dama noble que se preciara, debía invertir como mecenas de la caridad, de la religiosidad y del arte $^{44}$.

Confiamos en que las explicaciones aquí contenidas contribuyan a esclarecer y a comprender mejor la mudadiza peripecia vital de la Latina.

\section{FUENTES IMPRESAS Y BIBLIOGRAFÍA CITADAS}

Alcalá, A. y Sanz, J. (1998). Vida y muerte del principe Juan. Historia y Literatura. Valladolid: Junta de Castilla y León.

Alcalá, Pedro (1505). Vocabulista arávigo en letra castellana. En Arte para ligeramente saber la lengua aráviga. Granada: Juan de Arévalo.

Alvar Ezquerra, A. (2002). La educación de Isabel la Católica. Torre de los Lujanes, 48, 221-238.

Amador de los Ríos, J. (1877). Trabajos de la Academia. Sobre la publicación de las Batallas y quinquagenas del capitán Gonzalo Fernández de Oviedo. Boletín de la Real Academia de la Historia, 1(III), 209-217.

44. Recuérdese el valor artístico de la puerta del Hospital de la Latina, en Madríd, con escudos, las esculturas de San Francisco y San Onofre y, en el centro, las dos imágenes del Abrazo de San Joaquín y Santa Ana (Fernández Peña, 2005: 902); su retrato (Museo Lázaro Galdiano), así como los cuatro cenotafios platerescos, de alabastro, obra de Hernán Pérez de Alviz (Fernández Peña, 2014: 556), lujosos, de gran calidad, a pesar de que ella en su testamento dijera después que su enterramiento «se haga llanamente como se hace a un pobre de los que mueren en el hospital» (Arteaga, 1975:191). Se dice que Pedro Berruguete o algún pintor de su círculo realizó la tabla Virgen con el niño para el altar mayor de la capilla de uno de sus conventos. Este cuadro concreto fue realizado entre 1480-1500, mucho antes de que el convento estuviera siquiera proyectado. (La Virgen con el niño. https://www.museodelprado. es/coleccion/obra-de-arte/la-virgen-con-el-nio/e0b74e61-b3b5-4429-9a00-740ba8b9a6b4). 
Andreu Lorenzo, L. (2009). Vida y obra de Beatriz Galindo. Madrid: Eila, 2009.

Arroyal Espigares, P., Cruces Blanco, E. y Martín Palma, M. T. (2006). Beatriz Galindo: Fortuna y poder de una humanista en la corte de los Reyes Católicos. Baetica, 28, 299-324.

Arteaga, A. de (2007). Beatriz Galindo, La Latina: maestra de reinas, Madrid: Algaba.

Arteaga y Falguera, C. de la C. (1975). Beatriz Galindo La Latina. Madrid: Espasa Calpe.

Avalle Arce, J. B. (1980). Fernández de Oviedo, biógrafo inédito, muestras de una edición. Anuario de Letras, 18, 117-163, en línea: https:/dialnet.unirioja.es/servlet/ articulo? codigo $=31302$.

Baranda, N. (2004). Mujeres y cultura letrada en la época de Isabel la Católica. Ínsula: revista de letras y ciencias humanas, 691-692, 27-28.

Baury, B. (2021). Thérèse de Carthagène. Bosquet des malades. Admiration des oeuvres de Dieu. Paroles et silende d'une femme dans la Castille du Xve siècle. París: E-Spania Boolks.

Belda Plans, J. (2013). Grandes personajes del Siglo de Oro Español. Madrid: Ediciones Palabra.

Beltrán de Heredia, V. (1970, 1971). Cartulario de la Universidad de Salamanca (12181600). Salamanca: Ediciones Universidad de Salamanca, I y III.

Benito Ruano, E. (1989). El libro del limosnero de Isabel la Católica. Madrid: Ministerio de Asuntos Sociales.

Bermejo Cabrero, J. L. (1979). Los primeros secretarios de los reyes. Anuario de historia del derecho español, 49, 186-296.

Borreguero Beltrán, C. (2011). Puellae doctae en las cortes peninsulares. Dossiers Feministes, $15,76-100$.

Cahill Marrón, E. M. (2020). Veritas temporis Filia: 'Catalina de Aragón y la transformación de la educación regia femenina'. Atalaya, 20, en línea https://journals.openedition. org/atalaya/5031.

Carabias Torres, A. M. (2012a). Colegios mayores y letrados. 1406-1416. En C. Flórez Miguel et al. (Eds.), La primera Escuela de Salamanca (1406-1516). Salamanca: Ediciones Universidad de Salamanca, 15-34, en línea: https://gredos.usal.es/handle/10366/122375.

Carabias Torres, A. M. (2012b). ¿La muerte del letrado? Consideraciones sobre la tipología del oficial español en el siglo XVIII. En S. de Dios y E. Torijano (Coords.), Cultura política y práctica del derencho. Juristas de Salamanca siglos XV-XX (pp. 143-238). Salamanca: Ediciones Universidad de Salamanca, en línea: https://gredos.usal.es/ handle/10366/124008.

Carabias Torres, A. M. (2019). Beatriz Galindo y Lucía de Medrano: ni maestra de reinas ni catedrática de derecho canónico. Investigaciones históricas, época moderna y contemporánea, 39, 179-208, en línea: https://doi.org/10.24197/ihemc.39.2019.179-208.

Carabias Torres, A. M. y Mateos Díez, J. J. (2021). Grande del Brío, Ramón, Beatriz Galindo y Lucía de Medrano. La Latina y la catedrática [reseña]. Tiempos Modernos, 11(42), en línea http://www.tiemposmodernos.org/tm3/index.php/tm/article/view/5581.

Casey, J. (2009). El entramado hereditario y El matrimonio concertado. En J. Casey (Ed.), Familia, poder y comunidad en la España moderna: los ciudadanos de Granada (15701739) (pp. 133-183). València: Universitat de València.

Caso, Á. (2019). Las olvidadas: Una historia de mujeres creadoras. Barcelona: Planeta.

Ediciones Universidad de Salamanca / @®@

Stud. his., H. ${ }^{a}$ mod., 43, n. 2 (2021), pp. 71-104 
Castellano Castellano, J. L. (2007). La movilidad social y lo contrario. En I. Gómez, La movilidad social en la España del Antiguo Régimen (pp. 5-18). Granada: Comares.

Cátedra García, P. y Rojo Vega, A. (2004). Bibliotecas y lecturas de mujeres: siglo XVI. Madrid: Instituto de Historia del libro y de la lectura.

Clemencín, D. (1820). Elogio de la Reina Católica Doña Isabel: leído en la Junta Pública que celebro la Real Academia de la Historia, el día 31 de Julio de 1807. Madrid: Imprenta Sancha.

Coduras Bruna, M. (2015). Por el nombre se conoce al hombre. Estudios de antroponimia caballeresca. Zaragoza: Prensas de la Universidad de Zaragoza.

Covarrubias, S. de (1611). Tesoro de la lengua castellana o española. Madrid: Luis Sánchez.

Cruces Blanco, E. (1997). La guerra como promoción social: la familia Ramírez de Madrid en el Reino de Granada En M. González Jiménez et al. (Ed.), La Península Ibérica en la era de los descubrimientos (1391-1492). Actas III Jornadas Hispano-Portuguesas de Historia Medieval (II, pp. 1405-1419). Sevilla: Junta de Andalucía.

Cuart Moner, B. (2004). La larga marcha de las historias de España en el siglo XVI. En R. García Cárcel (Coord.), La construcción de las Historias de España (pp. 45-126). Madrid: Fundación Carolina. Centro de Estudios Hispánicos e Iberoamericanos. Marcial Pons Historia.

Dedieu, J. P. y Windler, C. (1998). La familia: ¿una clave para entender la historia política? El ejemplo de la España moderna. Studia Historica. Historia Moderna, 18, 201-233.

Díez Garretas, M. J. (2008). La lectura y la escritura en la casa y corte de Isabel la Católica. En P. Castañeda Delgado et al. (Ed.), V centenario de Isabel la Católica. XVI Simposio de Historia de la Iglesia en España y América (pp. 131-156). Córdoba: Obra Social de Caja Sur.

Earenfight, T. (2016). Raising Infanta Catalina de Aragón to be Catherine, Queen of England. Anuario de Estudios Medievales, 46(1), 417-443.

Esperabé de Arteaga, E. (1914). Historia pragmática e interna de la Universidad de Salamanca. Salamanca: F. Núñez Izquierdo, I.

Fernández de Córdoba, Á. (2002). La corte de Isabel I: ritos y ceremonias de una reina (1474-1504), Madrid: Dykinson, 2002.

Fernández de Oviedo, G. (1989). Batallas y quinquagenas. J. A. de los Ríos y Padilla (transcripción); J. Pérez de Tudela y Bueso (Ed.). Salamanca: Ediciones de la Diputación de Salamanca.

Fernández de Oviedo, G. (2006). Libro de la Cámara Real del Príncipe Don Juan, oficios de su casa y servicio ordinario. S. Fabregat Barrios (Ed.). Valencia: Universidad de Valencia, en línea: http://parnaseo.uv.es/editorial/camarareal/Camarareal.pdf.

Fernández Peña, R. M. (2005). La Concepción Inmaculada en el arte: El abrazo ante «La Puerta Dorada». En F. J. Campos y Fernández de Sevilla (Coord.), La Inmaculada Concepción en España: religiosidad, historia y arte (pp. 981-908). El Escorial: Instituto Escurialense de Investigaciones Históricas y Artísticas.

Fernández Peña, R. M. (2014). El arte funerario en España. Los enterramientos de don Francisco Ramírez y de su esposa doña Beatriz Galindo. Siglo XVI. En F. J. Campos y Fernández de Sevilla (Coord.), El mundo de los difuntos: Culto, cofradías y tradiciones (pp. 545-560). El Escorial: Instituto Escurialense de Investigaciones Históricas y Artísticas. 
Fuente, V. de la (1884-1889). Historia de las Universidades, Colegios y demás establecimientos de la enseñanza en España. Madrid: Imprenta de la Viuda e Hija de Fuentenebro.

Gómez de Cibdareal, F. (1775). Centón epistolar del bachiller Fernán Gómez de Cibdareal. Generaciones y semblanzas del noble caballero Fernán Pérez de Guzmán. Claros varones de Castilla y letras de Fernando del Pulgar. Madrid: Imprenta Real de la Gazeta.

Gómez Molleda, D. (1955). La cultura femenina en la época de Isabel la Católica. Revista de Archivos, Bibliotecas y Museos, 61, 138-195.

González Marrero, M. C. (2005). La Casa de Isabel la Católica, espacios domésticos y vida cotidiana, Ávila: Institución Gran Duque de Alba.

González Marrero, M. C. (2009). Las mujeres de la Casa de Isabel la Católica. En J. Martínez Millán y M. P. Marçal Lourenço (Coords.), Las relaciones discretas entre las Monarquias Hispana y Portuguesa, Las Casas de las Reinas (siglos XV-XIX) (II, pp. 841-886). Madrid: Ediciones Polifemo.

Grande del Brío, R. (2020). Beatriz Galindo y Lucía de Medrano. La Latina y la catedrática. Salamanca: Reprografía Signo.

Guil Bozal, A. y Flecha García, C. (2015). Universitarias en España: de los inicios a la actualidad. Revista de historia de la educación latinoamericana, 17(24), 125-148.

Hespanha, A. M. (2006). Las estructuras del imaginario de la movilidad social en la sociedad del Antiguo Régimen. En F. Chacón y N.G. Monteiro (Eds.), Poder y movilidad social. Cortesanos, religiosos y oligarquías en la Península Ibérica (siglos XV-XIX) (pp. 21-42). Madrid: CSIC-Universidad de Murcia.

Huidobre Moya, J. M. (2017). Francisco Ramírez de Madrid 'El Artillero', casado con Beatriz Galindo, 'La Latina'. Hidalgos: la revista de la Real Asociación de Hidalgos de España, 550, 6-10.

Jiménez Calvente, T. (1966). Lucio Marineo Sículo y la nueva literatura humanistica. Los epistolarum familiarum libri XVII. Tesis doctoral. Madrid: CSIC.

Jiménez Calvente, T. (2001) Un siciliano en la España de los Reyes Católicos. Los Epistolarum familiarium libri XVII de Lucio Marineo Sículo. Alcalá de Henares: Universidad de Alcalá de Henares, 2001.

Jiménez Calvente, T. (2008). Maestros de latinidad en la corte de los Reyes Católicos

¿un idead de vida o una vida frustrada? Epistolarum familiarium libri XVII. En N. Salvador y C. Moya García (Coords.), La literatura en la época de los Reyes Católicos (pp. 127-144). Madrid: Iberoamericana.

Ladero Quesada, M. A. (1967). Castilla y la conquista del Reino de Granada. Valladolid: Universidad de Valladolid.

Ladero Quesada, M. A. (1969). Mercedes reales en Granada anteriores al año 1500. Hispania: Revista española de historia, 112, 355-424.

Llanos y Torriglia, F. de (1920). Una consejera de Estado. Doña Beatriz Galindo La Latina. Madrid: Reus.

Maestre Maestre, J. M. y Torreblanca López, M. (2008). En torno a la versión castellana de la Historia de Juan II escrita por Lucio Marineo Sículo. En J. M. Maestre Maestre et al., Humanismo y pervivencia del mundo clásico: homenaje al profesor Antonio Prieto (III, pp. 1177-1230). Madrid, C.S.I.C.

Ediciones Universidad de Salamanca / 요 Stud. his., H. ${ }^{a}$ mod., 43, n. 2 (2021), pp. 71-104 
Marcos Martín, A. (2007). Movilidad social ascendente y movilidad social descendente en la Castilla moderna. En I. Gómez González y M. L. López-Guadalupe Muñoz (Coord.), La movilidad social en la España del Antiguo Régimen (pp. 19-48). Granada: Comares.

Marineo Sículo, L. (1530a). L. Marinei Siculi regii historiographi Opus de rebus Hispaniae memorabilibus. Compluti: Michaelem de Eguia. URL: http://bdh.bne.es/bnesearch/ detalle/bdh0000193147.

Marineo Sículo, L. (1530b). Obra compuesta por Lucio Marineo Siculo Cronista de sus Magestades de las cosas memorables de España. Alcalá de Henares: Miguel de Eguía.

Marineo Sículo, L. (1939). Obra compuesta por Lucio Marineo Siculo Coronista $d[\mathrm{e}]$ sus Magestades de las cosas memorables de España. Alcalá de Henares: Juan de Brocar, 1539, en línea: https://bvpb.mcu.es/es/catalogo_imagenes/grupo. do?path=143394.

Márquez de la Plata y Ferrándiz, V. (2005). Mujeres renacentistas en la corte de Isabel la Católica. Madrid: Castalia, 2005.

Martín Baños, P. (2019). La pasión de saber. Vida de Antonio de Nebrija. Huelva: Universidad de Huelva.

Martín Postigo, M. S. (1959). La cancillería castellana de los Reyes Católicos. Valladolid: Universidad de Valladolid.

Martínez Alcorlo, R. (2017). 'En un arca de cuero castaño': los libros de Isabel, primogénita de los Reyes Católicos. En J. C. Ribeiro Miranda (Coord.), En Doiro, antr'o Porto e Gaia: Estudos de Literatura Medieval Ibérica (pp. 695-710). Porto: Estratégias Criativas.

Martínez Alcorlo, R. (2020). Puellae doctae en la corte e los Reyes Católicos (1470-1555): educación, literatura y mecenazgo. Atalaya, 20, en línea: https://journals.openedition. org/salor/4896.

Mateos Díez, J. J. (2019). Luisa de Medrano o Lucía de Medrano Apuntes críticos para una biografía, en línea: https://independent.academia.edu/JuanJos\%C3\% A9MateosDiez.

Matilla Tascón, A. (2000). Beatriz Galindo, Francisco de Madrid y su familia. Madrid: Instituto de Estudios Madrileños.

Morales Muñiz, D. C. (s.a.). Beatriz de Bobadilla, en Real Academia de la Historia, Diccionario Biográfico electrónico, en línea: https://dbe.rah.es/biografias/13800/ beatriz-de-bobadilla.

Muñoz Fernández, Á. (2000). Relaciones femeninas y activación de los mecanismos del privilegio y merced. La Casa de Isabel I de Castilla. E C. Segura y A.I. Cerrada. (Coords.), Las mujeres y el poder: representaciones y prácticas de vida (pp. 115-134). Madrid: A. C. Al-Mudayna.

Nebrija, A. de (1495). [Vocabulario español-latino]. Salamanca: [Impresor de la Gramática castellana].

Nebrija, A. de (1516). Vocabulario de romance en latín hecho por el doctíssimo maestro Antonio de Nebrissa nuevamente corregido y augmentado más de diez mill vocablos de los que antes solía tener. Sevilla: Juan Varela de Salamanca.

Oettel, T. (1935). Una catedrática en el siglo de Isabel la Católica. Boletín de la Real Academia de la Historia, 107, 289-368.

Pelaz Flores, D. (2020). Aprendiendo el oficio de reinar. Formación cultural e infancia de las hijas de Isabel la Católica. Atalaya, 20, en línea: https://doi.org/10.4000/atalaya.4906.

Pérez, J. (2005). Los judios en la España moderna. Madrid: Marcial Pons.

Pérez Samper, M. A. (2004). Isabel la Católica. Barcelona: Plaza y Janés.

Ediciones Universidad de Salamanca / @®@@ Stud. his., H. ${ }^{a}$ mod., 43, n. 2 (2021), pp. 71-104 
Pérez de Tudela y Bueso, J (s.a.). Gonzalo Fernández de Oviedo, en Real Academia de la Historia, Diccionario Biográfico electrónico, en línea: http://dbe.rah.es/biografias/9417/ gonzalo-fernandez-de-oviedo-y-valdes.

Porras Arboledas, P. (s.a.) Francisco Ramírez de Madrid, en Real Academia de la Historia, Diccionario Biográfico electrónico, en línea: http://dbe.rah.es/biografias/10856/ francisco-ramirez-de-madrid.

Porras Arboledas, P. (1995). El secretario francisco Ramírez de Madrid. Apuntes para una biografía. Espacio, Tiemo y Forma, Serie III, $H^{a}$ Medieval, 8, 169-181.

Porras Arboledas, P. (1996). Francisco Ramírez de Madrid (144?-1501). Primer madrileño al servicio de los Reyes Católicos. Madrid: Comunidad de Madrid. Consejería de Educación y Cultura.

Porras Arboledas, P. (2006). Beatriz Galindo 'La Latina' (1465-1535). Apuntes para una biografía. Qalat. Revista de Historia y Patrimonio de Motril y Costa de Granada, V, 248-261.

Rábade Obradó, M. P. (2007). La educación del príncipe en el siglo XV: del Vergel de los príncipes al Diálogo sobre la educación del príncipe Juan. Res Publica, 18, 163-178.

Rábade Obradó, M. P. (2016). Construcción y deconstrucción de un personaje, Beatriz Galindo frente a su mito, en Cahiers d'études hispaniques medievales, 39, 165-182.

Ramos Santana, M. C. (s.a.). Lucio Marineo Sículo, en Real Academia de la Historia, Diccionario Biográfico electrónico, en línea: http://dbe.rah.es/biografias/11677/luciomarineo-siculo.

Real Academia Española (1729). Diccionario de la lengua castellana, en que se explica el verdadero sentido de las voces, su naturaleza y calidad, con las phrases o modos de hablar, los proverbios o refranes, y otras cosas convenientes al uso de la lengua... Madrid: Francisco del Hierro. Tomo II.

Real Academia Española (1734). Diccionario de la lengua castellana, en que se explica el verdadero sentido de las voces, su naturaleza y calidad, con las phrases o modos de hablar, los proverbios o refranes, y otras cosas convenientes al uso de la lengua [...].Tomo quarto. Que contiene las letras G.H.I.J.K.L.M.N. Madrid: Imprenta de la Real Academia Española, por los herederos de Francisco del Hierro.

Rivera Garretas, M. M. (1997). Las prosistas del humanismo y del Renacimiento (14001550). En I. M. Zavala (Coord.), Breve historia feminista de la literatura española (en lengua castellana), IV (La literatura escrita por mujer, desde la Edad Media hasta el siglo XVIII) (pp. 83-130). Barcelona: Anthorpos.

Rivera Martín, R. (2000). Estudio filológico sobre de Rebus Hispaniae Memorabilibus Libri $I: V$ de Lucio Marineo. Tesis doctoral en línea: https://eprints.ucm.es/id/eprint/3490/.

Sainz, Á. (2020). 'El Artillero' y 'La Latina' [Francisco Ramírez y Beatriz Galindo]. En M. Sanz (Coord.), A la sombra. Actores secundarios de la Historia. Granada: Alhulia, 135-148.

Sánchez Salor, E. (2020). Mujeres humanistas en el siglo XVI. Un desiderátum teórico. En R. M. Martínez de Codes y C. Chaparro Gómez (Coords.), La mujer en la Europa renacentista y en el Nuevo Mundo (pp. 271-298). [s.1.]: Fundación Academia Europea e Iberoamericana de Yuste.

Salvador Miguel, N. (2004). La instrucción de Isabel la Católica, los años cruciales (14511467). Arbor, Ciencia, pensamiento y cultura, 701, 107-128.

Salvador Miguel, N. (2008). Isabel la Católica. Educación, mecenazgo y entorno literario. Alcalá de Henares: Centro de Estudios Cervantinos, 2008. 
Santa Cruz, A. de (1951). Crónica de los Reyes Católicos, ed. J. de M. Carriazo. Sevilla: Escuela de Estudios Hispano-Americanos.

Segura Graíño, C. (s.a.). Beatriz Galindo. La Latina, en Real Academia de la Historia, Diccionario Biográfico electrónico, en línea: http://dbe.rah.es/biografias/10051/ beatriz-galindo.

Segura Graíño, C. (1994). Las sabias mujeres en la corte de Isabel la Católica. En M. M. Graña Cid (Coord.), Las sabias mujeres, educación, saber y autoría (pp. 175-187). Madrid: Asociación Cultural Al-Mudayna.

Segura Graíño, C. (2005). La educación en la Corte de Isabel I de Castilla. En C. Flecha García et al. (Eds.). Mujeres y Educación: saberes, prácticas y discursos en la historia (pp. 321-329). Madrid: Miño y Dávila.

Segura Graíño, C. (2007). La educación de las mujeres en el tránsito de la Edad Media a la Modernidad. Historia de la Educación, 26, 65-83.

Segura Graíño, C. (2011). Beatriz Galindo. Ejemplo de humanista laica. Miscelánea Comillas: Revista de Ciencias Humanas y Sociales, 69(134), 293-304.

Serrano Sanz, M. (1903). Apuntes para una Biblioteca de Escritoras Españolas, I, [S.l.: s.n., s.a.] (Madrid)

Sigüenza, J. de (1909[1595-1605]). Historia de la orden de San Jerónimo. Madrid: Nueva Biblioteca de Autores Españoles, n. ${ }^{\circ} 12$.

Soria Mesa, E. (2000). El cambio inmóvil. Transformaciones y permanencias en una élite de poder (Córdoba, siglos XVI-XIX). Córdoba: Ediciones de la Posada.

Tremlett, G. (2017). Isabel la Católica. La primera gran reina de Europa. Madrid: Debate, en línea.

Torre, A. de la (1954). La casa de Isabel la Católica. Madrid: CSIC, 1954.

Torre, A. de la (1956). Maestros de los hijos de los Reyes Católicos. Hispania: Revista española de historia, 63, 256-266.

Torre, A. de la (1957). Unas noticias de Beatriz Galindo. Hispania, 17, 255-261.

Torre, A de la y Torre, E. A. de la (1955-1956). Cuentas de Gonzalo de Baeza, tesorero de Isabel la Católica. Madrid: C.S.I.C. I: 1955; II: 1956.

Val Valdivieso, I. del (2003). Las mujeres en la Universidad: de la Edad Media al siglo XX. En R. Anguita (Coord.), Las mujeres en la Universidad de Valladolid (pp. 17-38). Valladolid: Universidad de Valladolid.

Val Valdivieso, I. del (2006a). Isabel la Católica y la educación. Aragón en la Edad Media, $19,555-562$.

Val Valdivieso, I. del (2006b). Del analfabetismo a la autoría: las mujeres en la Edad Media. En S. Gil-Albarellos y M. Rodríguez Pequeño (Eds.), Ecos silenciados: la mujer en la literatura española, siglos XII-XVIII (pp. 39-53). Segovia: Junta de Castilla y LeónInstituto Castellano y Leonés de la Lengua.

Val Valdivieso, I. del (2004). Isabel I de Castilla 1451-1504. Madrid: Ediciones del Orto.

Val Valdivieso, I. del (2011) La educación en la corte de la reina Isabel la Católica. Miscelánea Comillas, 69(134), 255-273.

Val Valdivieso, I. del (2013). La educación del príncipe y de las infantas en la corte castellana al final del siglo XV. ActaLauris, 1, 7-31.

Valdeón Baruque, J. (Ed.) (2003). Arte y cultura en la época de Isabel la Católica. Valladolid: Ámbito, 2003. 